Wu, M., Sabbaghian, N., Xu, B., Addidou-Kalucki, S., Bernard, C., Zou, D., Reeve, A., Eccles, M., Cole, C., Choong, C., Charles, A., Tan, T., Iglesias, D., Goodyer, P. and Foulkes, W. (2013), Biallelic DICER1 mutations occur in Wilms tumours. J. Pathol., 230: 154-164. doi: $10.1002 /$ path.4196

Copyright (c) 2013 Pathological Society of Great Britain and Ireland. Published by John Wiley \& Sons, Ltd.

This is the peer reviewed version of the following article: Wu, M., Sabbaghian, N., Xu, B., Addidou-Kalucki, S., Bernard, C., Zou, D., Reeve, A., Eccles, M., Cole, C., Choong, C., Charles, A., Tan, T., Iglesias, D., Goodyer, P. and Foulkes, W. (2013), Biallelic DICER1 mutations occur in Wilms tumours. J. Pathol., 230: 154-164. doi: 10.1002/path.4196, which has been published in final form at http://dx.doi.org/10.1002/path.4196.

This article may be used for non-commercial purposes in accordance with Wiley Terms and Conditions for self-archiving.

This version was made available in the UWA Research Repository on 1 June 2014 in compliance with the publisher's policies on archiving in institutional repositories.

Use of the article is subject to copyright law. 


\section{Biallelic DICER1 mutations occur in Wilms tumours}

$\mathrm{MK} \mathrm{Wu}^{1}$, N Sabbaghian ${ }^{1}$, B Xu${ }^{2}$, S Addidou-Kalucki ${ }^{1}$, C Bernard ${ }^{2}$, D Zou ${ }^{3}$, AE Reeve ${ }^{3}$, M

Eccles $^{4}$, C Cole ${ }^{5}$, CS Choong ${ }^{5,6}$, A Charles ${ }^{5,7}$, TY Tan ${ }^{8}$, DM Iglesias ${ }^{9}$, PR Goodyer ${ }^{9}$; WD Foulkes ${ }^{1,10,11}$

${ }^{1}$ Department of Medical Genetics, Lady Davis Institute, Jewish General Hospital, McGill University, Montreal, QC, Canada; ${ }^{2}$ Division of Pediatric Pathology, Montreal Children's Hospital, McGill University Health Centre, Montreal, Quebec, Canada; ${ }^{3}$ Cancer Genetics Laboratory, Department of Biochemistry, University of Otago, Dunedin, New Zealand; ${ }^{4}$ Department of Pathology, Dunedin School of Medicine, University of Otago, PO Box 913, Dunedin, New Zealand; ${ }^{5}$ School of Paediatrics and Child Health (SPACH), University of Western Australia (M561) Crawley, Western Australia; ${ }^{6}$ Department of Endocrinology, Princess Margaret Hospital for Children, Perth, Western Australia; ${ }^{7}$ Department of Paediatric Pathology, Princess Margaret Hospital for Children, Perth, Western Australia; ${ }^{8}$ Victorian Clinical Genetics Services, Murdoch Children's Research Institute, Royal Children's Hospital Melbourne Australia; ${ }^{9}$ Department of Pediatrics, Montreal Children's Hospital Research Institute, McGill University, Montréal, Québec, Canada; ${ }^{10}$ Research Institute of the McGill University Health Centre, Montréal, Québec, Canada; ${ }^{11}$ Program in Cancer Genetics, Depts Oncology and Human Genetics, McGill University, Montréal, Québec, Canada

Running title: DICER1 mutations in Wilms Tumour Correspondence: Dr. William D. Foulkes, at the Program in Cancer Genetics, Gerald Bronfman Centre for Clinical Research in Cancer, Department of Oncology, McGill University, 546 Pine Ave. West, Montreal, QC H2W 1S6, Canada, or at william.foulkes@mcgill.ca.

The authors declare no conflict of interest.

Word count: 3533 


\section{ABSTRACT}

DICER1 is an endoribonuclease central to the generation of microRNAs (miRNAs) and short interfering RNAs (siRNAS). Germ-line mutations in DICER1 have been associated with a pleiotropic tumour predisposition syndrome and Wilms tumour (WT) is a rare manifestation of this syndrome. Three WTs, each in a child with a deleterious germ-line DICER1 mutation, were screened for somatic DICER1 mutations and were found to bear specific mutations in either the RNase IIIa ( $n=1)$ or RNase IIIb domain $(n=2)$. In the two latter cases, we demonstrate that the germline and somatic DICER1 mutations were in trans, suggesting that the two-hit hypothesis of tumour formation applies for these examples of WT. Among 191 apparently sporadic WT, we identified 5 different missense or deletion somatic DICER1 mutations (2.6\%) in 4 individual WTs; one tumour has two very likely deleterious somatic mutations in trans in the RNase IIIb domain (c.5438A >G and c.5452G>A). In vitro studies of two somatic single base substitutions (c.5429A $>$ G and c.5438A $>$ G) demonstrate exon 25 skipping from the transcript, a phenomenon not previously reported in DICER1. Further we show that DICER1 transcripts lacking exon 25 can be translated in vitro. This study has demonstrated that a subset of WT exhibit two "hits" in DICER1, suggesting that these mutations could be key events in the pathogenesis of these tumours.

Key words: miRNA, pediatric tumours, exon splicing silencer 


\section{Introduction}

Wilms tumour (WT) (OMIM 194070) is the most common pediatric renal malignancy occurring in $~ 1 / 10000$ live births [1, 2]. WTs are considered to be an excellent model on which to study the proposed relationship between malignancy and aberrant differentiation [3]. Most WTs are sporadic, but at least 5\% are familial [1]. Syndromes associated with WT include Wilms tumour, aniridia, genitourinary anomalies, and mental retardation; WAGR (OMIM 194072), Wilms tumour, aniridia, genitourinary anomalies, mental retardation syndrome, and obesity; WAGRO (OMIM 612469), Beckwith-Wiedemann (OMIM 130650), Denys-Drash (OMIM 194080), and Perlman (OMIM 267000) [4-6]. WT has also recently been reported to occur in the DICER1 mutation-associated familial pleuropulmonary blastoma (PPB) syndrome (OMIM 601200) [7, 8]. Several genes have been identified as being somatically mutated in WT including WT1, CTNNB1, IGF2, TP53, WTX, DIS3L2, FBXW7, and MYCN [5, 9]. There are overlapping distributions of molecular abnormalities at 11p15, WTX, WT1 and CTNNB1 in WT [9, 10], but other genes could be contributing to the etiology of WT $[3,11-13]$. WT histopathology is heterogeneous and tumours associated with different types of nephrogenic rests and histologies tend to show different underlying genetic changes $[14,15]$. A revised model for WT ontogeny takes into account genetic data (WT1 status, 11p15 imprint control region 1 methylation status, gene expression patterns of other genes) and histological data [14]. Nevertheless, each WT is thought to be of monoclonal origin [16].

Forty years ago, it was hypothesized that the "two-hit" model for cancer could be a mechanism for WT [17]. According to this model, sporadic tumours develop following two independent 
events occurring in both copies of the same gene, while hereditary cases involve germ-line transmission of one altered gene and acquisition of a somatic mutation on the other allele. Although several studies in the 1980s reported WT1-affected WTs behaving in similar manner to retinoblastoma [18-22], subsequently, the "two-hit" model for WT has not been as strongly supported as it has been for retinoblastoma [12], perhaps due to genetic heterogeneity.

DICER1 (GenBank accession no: NG_016311.1; ENSEMBL: ENST000000343455) is an RNase endoribonuclease which catalyzes the cleavage of double-stranded RNA (dsRNA) substrates to produce both mature microRNAs (miRNAs) and short interfering RNAs (siRNAs) [23]. In the case of miRNAs, DICER1 cleavage produces 5' (5p) and 3' (3p) miRNAs form hairpin precursors. MiRNAs are, in turn, estimated to post-transcriptionally regulate the expression of $>30 \%$ of genes [24]. DICER1 is also involved in regulation of chromatin, alternative splicing, DNA replication timing, genome stability, and cellular senescence [25, 26]. DICER1 is mutated in the DICER1 mutation-associated familial PPB syndrome which includes PPB, cystic nephroma, ovarian Sertoli-Leydig cell tumours (SLCT), intraocular medulloepithelioma, pituitary blastoma, thyroid non-toxic goitres/cysts and other phenotypes [7, 8, 27-29].

DICER1 protein is organized in a series of domains of which the RNase IIIa and RNase IIIb domains are thought to dimerize intramolecularly with magnesium to form the active site of the enzyme [30-35] (Figure 1). Interestingly, DICER1 mutations in the RNase IIIb domain (c.49965535; p.1681-1845) were identified in $60 \%$ of nonepithelial ovarian cancers, especially SLCT [36, 37]. The RNase IIIb domain was considered to be a "hotspot" for mutation. As WT and ovarian SLCT are both part of the spectrum of neoplasms present in the DICER1-related 
pleiotropic tumour predisposition syndrome, we set out to investigate sporadic and familial WTs to determine whether a) somatic DICER1mutations were present in WT (with a focus on the RNase IIIb and/or RNase IIIa domains) and b) the "two-hit” hypothesis is supported in WTs with two DICER1 mutations.

\section{Materials and Methods}

Hereditary cases

Case 1 is a male diagnosed with WT at age 2 years (2 yrs) (Figure 1a). The WT was described as a triphasic nephroblastoma with a prominent blastemal component; scattered areas were dominated by immature tubules with primitive to more mature epithelium. There was no evidence of anaplasia, no evidence of nephrogenic rests, and no involvement of one regional lymph node. The adjacent uninvolved kidney was histologically normal.

Case 2 is a female diagnosed with WT at 5 yrs (Figure 1b). This lesion was described as a triphasic nephroblastoma with no evidence of anaplasia. Two of 7 regional lymph nodes were involved by tumour. There was no rhabdomyoblastic differentiation and no evidence of nephrogenic rests. Case 2 also developed a multinodular goiter (MNG) at 10 yrs.

Case 3 is a male diagnosed with WT at 4 yrs (Figure 1c). This tumour was described as a triphasic nephroblastoma with predominant primitive blastemal component comprising twothirds of the tumour with primitive tubular structures and focal spindle cells indicating the presence of epithelial and stromal components respectively. There was diffuse anaplasia, mostly involving blastema but focally mesenchymal tumour cells, with markedly enlarged 
hyperchromatic nuclei and multipolar mitotic figures. There was no evidence of nephroblastomatosis.

Sporadic WTs

191 sporadic WTs were assembled of which 120 were derived from fresh frozen WTs and 71 were formalin-fixed paraffin-embedded (FFPE) sporadic WTs (Table 1). The fresh frozen WT DNA samples were obtained from North America and Western Australia. The FFPE WT samples were obtained from Canada and New Zealand. Sex ratio, age at diagnosis, and ethnic distribution of samples is shown in Table 1.

Screening DICER1 in hereditary WT

The three hereditary WT cases (Figure 1a-c) contain germline mutations that have previously been reported [8]. Somatic mutations were determined by PCR from DNA derived from each WT [38] followed by Sanger sequencing (Genome Quebec).

Screening DICER1 in sporadic WT

DNA from 120 fresh frozen WTs was screened for the entire DICER1 gene and the 71 FFPE sporadic WTs were screened for DICER1 RNase IIIb and RNase IIIa domains. Screening the entire DICER1 gene was determined by PCR of region of interest (as in [38] with the exceptions for exon 3, 7, 10, and 22 (Table S1)). Exon 7 was amplified as described in [38] and exons 3, 10, and 22 were amplified using a Touchdown PCR program [39] with annealing temperature decreasing by $0.5^{\circ} \mathrm{C}$ from $65^{\circ} \mathrm{C}$ to $60^{\circ} \mathrm{C}$ followed by Sanger sequencing (Genome Quebec). DNA from FFPE tissue was extracted (QIAmp DNA FFPE Tissue kit or REPLI-g FFPE kit) and 
only RNase IIIb and RNase IIIa domains were screened (Table S2) amplified using the program above followed by Sanger sequencing (Genome Quebec).

\section{Determining phase of DICER1 mutations}

To determine the phase of mutations for cases 1 and 2, fresh frozen WTs were obtained, RNA was collected (TriReagent, Molecular Research Center, Inc.), cDNA was constructed (QuantiTect Reverse Transcription Kit, Qiagen), and PCR amplified (using primers 5'TAGTGGCATTTCCACCAAAC-3' and 5'-ACTGCACACACGGAGAGATG-3' for case 1 and 5'-TTCAACTCTTTATCTGCCAATTAACTC-3' and 5'- ACTGCACACACGGAGAGATG-3' for case 2). To determine phase of DICER1 mutations in somatic case N, a PCR fragment encompassing both mutations was amplified using primers 5'-TGGACTGCCTGTAAAAGTGG3' and 5'- TGAACTTTTCCCCTTTGATG-3'. PCR fragments were TA cloned into pCR-XLTOPO (Invitrogen). DNA from 10-40 clones was collected (QIAprep Spin Miniprep Kit, Qiagen) and sent for Sanger sequencing (Genome Quebec) using the primers described above. Institutional review board approval was granted to the study by at the relevant institutions.

Exonic Splicing Silencer (ESS) in vitro splicing experiment DNA from case 2 and case $\mathrm{N}$ was amplified using primers 5'ACTGCTCGAGGTTAGTGCTGTTCAAAAC-3' and 5'ACTGGGATCCCTGCAATCAAAATGAAAG -3’ and cloned in pSPL3 (Invitrogen). DNA was extracted from clones (QIAprep Spin Miniprep Kit, Qiagen) and verified to contain mutation of interest by Sanger sequencing (Genome Quebec) (data not shown). $2.5 \mu \mathrm{g}$ of each construct was transiently transfected into COS-1 cells (Lipofectamine, Invitrogen) for 24 hours. RNA was 
collected (TriReagent, Molecular Research Center, Inc.), cDNA was constructed (QuantiTect Reverse Transcription Kit, Qiagen), and PCR amplified using primers described[40]. PCR products were sequenced using the primers previously described [40] (Genome Quebec) as were the upper band seen for the case N (Figure S3) that were gel purified (QIAquick gel extraction kit, Qiagen).

\section{Western blot analysis of DICER1 lacking exon 25}

The pCAGGS-FLAG-DICER1 construct was a gift from A. Gurtan [41]. A control pCAGGSFLAG vector was created by excising DICER1 from pCAGGS-FLAG-DICER1 using HindIII (New England Biolabs). A pCAGGS-FLAG-DICERdeltaExon25 construct was made by PCRamplifying the truncated portion from pTC1 (see Figure 3a) with 5'CGCTTAGAATTCCTGGGAGA-3'/5'-CAGTGGTACCTCAGCTATTGGGAAC-3', restricting with SacI/KpnI (New England Biolabs) and cloning into SacI/KpnI restricted pCAGGS-FLAG-DICER1. $15 \mu$ g of each construct was transiently transfected into COS-1 cells (Lipofectamine, Invitrogen) for 24 hours. Protein lysates were collected as described preciously [42]. $50 \mu \mathrm{g}$ of each protein lysate was loaded onto a Criterion XT precast 4-12\% Bis-Tris Gel (BioRad), transferred to nitrocellulose, and probed with 1:1000 dilution of anti-FLAG M2 antibody (Agilent Technologies), 1:2000 dilution anti-Dicer antibody (D38E7, Cell Signaling Technology, Inc.), and 1:2000 dilution of anti-actin antibody (I-19, Santa Cruz Biotechnology). 


\section{Results}

Somatic DICER1 mutations in three WTs associated with germline DICER1 mutations

The three hereditary WT cases are summarized in Figure 1a-c [8]. All germ-line mutations cause frameshifts which create premature termination codons (PTCs) (Figure 1, Figures S1-S3). The somatic mutations seen in cases 1 and 2 affect the RNase IIIb domain while the somatic mutation in case 3 affects the RNase IIIa domain (Figure $1 \mathrm{~d}$ and e). The somatic mutations for both case 1 and 3 are predicted to be probably damaging by

Polyphen2(http://genetics.bwh.harvard.edu/pph2/index.shtml) [43] and to affect protein function by SiftBlink(http://sift.jcvi.org/www/SIFT_BLink_submit.html) [44] (Figure 1f).

The germline and somatic mutations for cases 1 and 2 were shown to be in trans (Figures S1 and S2). We were unable to determine phase in case 3. Notably, the sister of case 3 was diagnosed with a cystic nephroma, but a search for mutations in the RNase IIIa or RNase IIIb domains did not reveal any variants (data not shown).

While attempting to determine the phase of mutations in case 2, we noted that the somatic mutation resulted in loss of exon 25, formally c.5429A>G; r.5365_5527delCTTAGGAGATCTGAGGAGGATGAAGAGAAAGAAGAGGATATTGAAG TTCCAAAGGCCATGGGGGATATTTTTGAGTCGCTTGCTGGTGCCATTTACATGGATA GTGGGATGTCACTGGAGACAGTCTGGCAGGTGTACTATCCCATGATGCGGCCACTAA TAG (Figures S2). We postulate that c.5429A $>\mathrm{G}$ has resulted in a net gain of one additional exonic silencing site (ESS) in exon 25 (Figure S6, http://genes.mit.edu/fas-ess/ [45]). Furthermore, the EX-SKIP program (http://ex-skip.img.cas.cz/ [46]) predicts that the c.5429A>G variant has a higher chance of exon skipping than the wild type allele. A minigene experiment 
comparing splicing efficiency of exon 25 with and without c.5429A $>$ G supports the notion that c.5429A >G promotes exon 25 exclusion (Figure 3). Using RT-PCR, we show that the exon 25depleted transcript is tumour-specific (Figure S2d). Sequencing of RT-PCR products in the WT of case 2 confirmed the exon 25 skip in the lower species while the upper species showed some evidence of c.5429A>G, suggesting that its ability to promote exon 25 exclusion is not $100 \%$ efficient (Figure S2d).

To assess whether or not an exon-25 depleted DICER1 transcript could be translated, we performed Western blots against FLAG and DICER1 in exogenously over-expressed a FLAGtagged version of this construct (pCAGGS-FLAG-DICERdeltaexon25) along with full-length DICER1 (pCAGGS-FLAG-DICER) (Figure 4). The exon-25 depleted construct is expressed albeit to a lower degree than full-length DICER1.

\section{Screening sporadic WT samples for DICER1 mutations}

Several intronic mutations were observed (Table S3). Twelve different coding mutations were observed (6.1\%) of which 5 (2.6\%) were either missense or deletion mutations (Table 1, Figure 2), and the remaining 7 (3.6\%) were silent mutations (Figure S7). Missense/deletion mutations were seen in four individual WTs (cases C, M, N, and X, Figure 2). With the exception of case $\mathrm{C}$, all of the missense/deletion mutations resided in either the RNase IIIb or RNase IIIa domain (Figure 2). Only one missense mutation (c.2614G>A = rs149242330) was previously assigned an rs number which suggests that all other missense/deletion mutations reported here are novel DICER1 variants. 
Case $\mathrm{N}$ was found to have 2 mutations (c. 5438A $>\mathrm{G}$ and c.5452G $>\mathrm{A}$, see Figure 2). These mutations were in trans (see Figure S4) and due to the presence of clones bearing neither mutation, we reason that both of the mutations were acquired somatically. To prove this point, we obtained constitutional DNA from this case, which was found not to bear either c.5438A $>\mathrm{G}$ or c.5452G>A (data not shown). The mutation (c.5452G>A; p.A1818T) is predicted to be probably damaging by Polyphen2 and to affect protein function by SIFTBLink (Table 2). In silico analysis showed that exon 25 with c.5438A $>\mathrm{G}$ had a net gain of two additional ESSs (Figure S5). Other in silico analyses of exon 25 with or without c.5438A $>$ G suggests that c.5438A $>\mathrm{G}$ would result in exon 25 exclusion and a minigene experiment supports this hypothesis (Figure 3).

Cases $\mathrm{C}, \mathrm{M}$, and $\mathrm{X}$ each possessed a single DICER1 mutation (Figure 2). The mutation in case $\mathrm{C}$ was near the PAZ domain (c.2614G>A = rs149242330; p.A872T) and is predicted to be probably damaging by Polyphen2 and tolerated by SIFTBLink (Table 2). Cconstitutional DNA for case $\mathrm{C}$ determined that it was a germline mutation (data not shown). The mutation in case $\mathrm{M}$ was in the RNase IIIb domain (c.5330T>A; p.L1777H) is predicted to be possibly damaging by Polyphen2 and to be tolerated by SIFTBLink (Table 2) and is a germline mutation (data not shown). No constitutional DNA was available for case X, therefore we cannot determine if the mutation was of germline or somatic origin. The mutation in case $\mathrm{X}$ was between the PAZ and RNase IIIa domains (c.3329A>G; p.I1110S) is predicted to be benign by Polyphen2 and tolerated by SIFTBLink (Table 2). 


\section{Discussion}

Our identification of three WTs with two DICER1 mutations in trans support a "two-hit" hypothesis of tumour formation. The germline frameshift mutations in each of the hereditary WT cases are probably subject to nonsense mediated decay (NMD) due to the presence of PTCs. As was demonstrated for other germ-line DICER1 mutations [47], cloning results for cases 1 and 2 show a lack of PTC-bearing clones which supports the notion of NMD of these transcripts (Figures S1 and S2). In addition, we identified one sporadic WT with two somatic mutations in trans, both of which were located in the RNase IIIb domain.

While residues E1705, E1709, D1713, D1810, and E1813 were identified as being important for Mg2 $^{+}$binding and intramolecular dimerization [34], Heravi-Moussavi et al. (2012) suggest that metal binding sites reside at residues 1705, 1709, 1810 and 1813 and active site residues are positioned at 1702 and 1729 [37]. Therefore, the somatic mutation observed in case 1

(c.5138A>C; p.D1713A, Figure 1f) is likely to negatively affect the miRNA-generating ability of DICER1 in this WT. In case 2, DICER1 transcript lacking exon 25 missing, would lack the majority of its RNase IIIb domain (we predict p.E1788fsX41) including active site residues 1810 and 1813 [34, 37]. An in vitro over-expression of a FLAG-tagged DICER1 construct lacking exon 25 showed that this construct can be translated albeit not as efficiently as intact DICER1 (Figure 4). In vitro cleavage assays of synthesized DICER1 RNase IIIb domain bearing either D1810A or E1813A showed a reduced ability to cleave dsRNA substrate [34] which would suggest that miRNA generation may be compromised in case 2. To our knowledge, c.5429A>G is the first example of a single base substitution in DICER1 leading to exon skipping. The idea 
that ESSs can contribute to human disease is an emerging concept $[46,48,49]$ which seems to apply in this particular case of DICER1-related WT.

Since the data for cases 1 and 2 show that these tumours have two in trans DICER1 mutations, we suggest that kidney cells bearing defective DICER1 are predisposed to develop WT (Figure 5A). In this way, the "two-hit” model [17] may still apply for DICER1- affected WTs. We further suggest that it is the aberrant miRNA-generating function of the defective DICER1 that is responsible for the deleterious effects. The same model (Figure 4A) may apply to the SLCT samples with two in trans DICER1 mutations SLCT-19 (germline c.5018_5021delTCAA + somatic c.5125G>A) and SLCT-20 (germline c.2528delC + somatic c.5125G>A), reported previously [37].

Since case $\mathrm{N}$ had two in trans somatically acquired mutations (c.5438A $>\mathrm{G}$ or c.5452G $>\mathrm{A}$, Figures 2, S4) and had no mutations in WT1 or CTNNB1 (data not shown), we suggest that this tumour may be an example where two somatic hits to the RNase IIIb domain were sufficient for pathogenesis (Figure 5B). Furthermore, as we have demonstrated that c.5438A $>$ G results in exon 25 exclusion in DICER1 transcripts (Figure 3), and like case 2, we suggest that miRNA generation in case $\mathrm{N}$ would be compromised due reduced levels of DICER1 protein lacking key residues 1810 and 1813. We note that a number of papers using Dicer1-null mouse embryonic stem cells were derived from a construct with loxP sites located around the RNase IIIb domain. We suggest, in light of our protein expression work here, that these Dicer1-null cells may in fact produce low levels of DICER1 protein lacking the RNase IIIb domain [41, 50, 51]. 
Twenty of the 95 samples provided by the Children’s Oncology Group (COG) (Table 1)

possessed somatic WT1 mutations (data not shown). Of the three WTs with DICER1 mutations identified from the Whole DICER1 Screening set, neither of the two cases (M and N) that have available data possessed WT1 mutations (data not shown). Cases 1, 2, and 3 also did not have WT1 defects and Case 2 also does not have any abnormalities at $11 \mathrm{p} 13$ or $11 \mathrm{p} 15$ by cytogenetic or SNP array analysis [52]. Given that the DICER1-related tumors (Table S4) do not have a remarkably distinct pathological appearance, it is possible that alternate initiating genetic lesions in WT1-mutated and DICER1-mutated WTs converge on the same genetic pathway to give rise to lesion formation.

For WTs where only one DICER1 mutation was identified (cases C, M, and X, Figure 2), there remains a small possibility that second hit occurred in regions not screened with our methodology (e.g. promoter, deep intronic regions, UTRs for all cases; mutations outside of RNase IIIa or IIIb for cases M and X). Case C (c.2614G>A = rs149242330; p.A872T) probably developed a WT due to WAGR syndrome since the child carries a genomic deletion coupled with a somatically acquired insertion in WT1 (c.1135_1138dupTACG), which is not accompanied by any other DICER1 or CTNNB1 mutations (data not shown). The position of the mutated DICER1 residues in cases $\mathrm{C}, \mathrm{M}$, and $\mathrm{X}$ suggest that they could influence the miRNA landscape. For example, mutation of the PAZ domain (Y971A,Y972A, E1036A) results in global reduction of miRNA processing [41], therefore case C (mutation just outside the PAZ domain) and possibly case X (mutation between PAZ and RNase IIIa domain) may be associated with a reduced number of miRNAs. Case M (c.5330T>A; p.L1777H) may have some impact on the miRNA generating ability of DICER1 since residue 1777 is within the RNase IIIb domain 
and may affect active site architecture and/or activity and/or protein-protein interactions. However, the clinical relevance of each of these mutations is as yet unexplored.

Now that a growing list of genes have been associated with initiation and progression of WT, it may be possible to consider stratification of WTs into groups: Scott et al (2012) have selected three groups on the basis of somatic mutations at WT1, CTNNB1, WTX and TP53, and imprinting at 11p15 [10]. Another stratification schema, based on gene expression, has also been proposed [14]. It is plausible that DICER1 mutation status and/or miRNA profiles may allow for further stratification of some of these sub-groups. Perhaps different WT genes may regulate a critical set of miRNAs needed for normal differentiation of renal progenitor cells.

RNase IIIb appears to be a "hotspot" for mutations in our set of WTs (e.g. cases 1, 2, M, and N; Table 1 and Figure 2). This phenomenon was first reported in non-epithelial ovarian cancers [37]. More recently, one such mutation was seen in a testicular germ cell tumour [53], but the pathogenicity of the observed variant is questionable. We have identified two familial WT cases (cases 1 and 2) and one sporadic WT case (case N) which all support the "two-hit" model of WT with respect to DICER1 (Figure 5A for cases 1 and 2, Figure 5B for case N). Moreover, WT arising in children with germline DICER1 mutations (Table S4) that have not been investigated genetically may bear a "second hit" in DICER1. We postulate that in some WTs, DICER1 mutations act as key "driver-type” mutations [54] and that these two hits maybe sufficient for tumorigenesis: cells with only RNase IIIb-defective DICER1 may have an altered variety and/or quality of miRNAs, particularly of the 5p variety [41]. This selective loss of 5p-miRNAs could underpin the oncogenic process by promoting proliferation while at the same time inhibiting 
differentiation. Notably, human cancers bearing mutant DICER1 RNase IIIb mutations at its metal binding sites have a dramatic loss in processing of mature 5p-miRNAs [51]. Two of the single base substitutions (c.5429A > G and c.5438A>G) appear to promote exon 25 exclusion from DICER1 transcripts. We have shown that exon 25 depleted transcripts can be translated (Figure 4), but whether these mutant proteins alter miRNA production in the same way as a fulllength transcript carrying a disease-associated missense mutation in RNase IIIb remains to be determined. The concept of miRNA [55-57] and DICER1 [58] being critical in normal kidney development and development of kidney disease has been previously discussed [59]. Identifying the specific miRNAs that are missing from DICER1-affected WTs and comparing and contrasting them with those miRNAs that are altered in WT1-affected WTs may provide clues to the nature of other genes whose over-expression contributes to WT formation. This could lead to further understanding of all the processes that link WT pathogenesis to normal kidney development. 


\section{Author contributions}

MKW conceived and carried out cloning and ESS experiments, created figures, and wrote the manuscript. NS and MKW carried out whole gene screening. SA-K assisted MWK in conducting RNase IIIa/b screening of FFPE WT. BX, CB, DZ, AER, ME, CC, CSC, AC, TYT, DMI, and PRG provided samples and detailed discussions. WDF led the project. All authors were involved in writing the paper and had final approval of the submitted version.

\section{List of abbreviations}

WT= Wilms tumour

DUF= domain of unknown function

dsRBD $=$ double stranded RNA binding domain

COG-RTS= Children’s Oncology Group Renal Tumours Study

FFPE $=$ formalin-fixed paraffin embedded

ESS= exonic splicing silencer

MNG= multinodular goitre

UTR= untranslated region

\section{Acknowledgments}

We would like to thank Mr François Plourde, Ms. Nancy Hamel, Dr John R. Priest, Dr Megan Dishop, and Dr Nicole Graf for their assistance and helpful comments. The Children's Oncology Group Renal Tumours Study (COG-RTS) provided frozen tumours for this study and we acknowledge the help of Dr. Vicki Huff in facilitating our work with the COG-RTS. We thank Carlos Alvarado for COS-1 cells, Dr. Lilian Amrein for assistance with Western blots, Dr. Marc 
Fabian for Dicer antibody and Dr. Denis Gaucher for FLAG antibody. This work was funded by the Jewish General Hospital Foundation. 


\section{$\underline{\text { References }}$}

1. Huff, V., Wilms tumor genetics. Am J Med Genet, 1998. 79(4): p. 260-7.

2. Rivera, M.N. and D.A. Haber, Wilms' tumour: connecting tumorigenesis and organ development in the kidney. Nat Rev Cancer, 2005. 5(9): p. 699-712.

3. Van Heyningen, V. and N.D. Hastie, Wilms' tumour: reconciling genetics and biology. Trends Genet, 1992. 8(1): p. 16-21.

4. Sharpe, C.R. and E.L. Franco, Etiology of Wilms' tumor. Epidemiol Rev, 1995. 17(2): p. 415-32.

5. Md Zin, R., A. Murch, and A. Charles, Pathology, genetics and cytogenetics of Wilms' tumour. Pathology, 2011. 43(4): p. 302-12.

6. Astuti, D., et al., Germline mutations in DIS3L2 cause the Perlman syndrome of overgrowth and Wilms tumor susceptibility. Nat Genet, 2012. 44(3): p. 277-84.

7. Slade, I., et al., DICER1 syndrome: clarifying the diagnosis, clinical features and management implications of a pleiotropic tumour predisposition syndrome. J Med Genet, 2011. 48(4): p. 273-8.

8. Foulkes, W.D., et al., Extending the phenotypes associated with DICER1 mutations. Hum Mutat, 2011. 32(12): p. 1381-4.

9. Williams, R.D., et al., Subtype-specific FBXW7 mutation and MYCN copy number gain in Wilms' tumor. Clin Cancer Res, 2010. 16(7): p. 2036-45.

10. Scott, R.H., et al., Stratification of Wilms tumor by genetic and epigenetic analysis. Oncotarget, 2012. 3(3): p. 327-35.

11. Cowell, J.K., N. Groves, and P. Baird, Loss of heterozygosity at 11p13 in Wilms' tumours does not necessarily involve mutations in the WT1 gene. Br J Cancer, 1993. 67(6): p. 1259-61.

12. Strong, L.C., The two-hit model for Wilms' tumor: where are we 30 years later? Genes Chromosomes Cancer, 2003. 38(4): p. 294-9.

13. Wadey, R.B., et al., Loss of heterozygosity in Wilms' tumour involves two distinct regions of chromosome 11. Oncogene, 1990. 5(6): p. 901-7.

14. Gadd, S., et al., Clinically relevant subsets identified by gene expression patterns support a revised ontogenic model of Wilms tumor: a Children's Oncology Group Study. Neoplasia, 2012. 14(8): p. 742-56.

15. Huang, A., et al., Tissue, developmental, and tumor-specific expression of divergent transcripts in Wilms tumor. Science, 1990. 250(4983): p. 991-4.

16. Guertl, B., et al., Genetic clonality is a feature unifying nephroblastomas regardless of the variety of morphological subtypes. Virchows Arch, 2006. 449(2): p. 171-4.

17. Knudson, A.G., Jr. and L.C. Strong, Mutation and cancer: a model for Wilms' tumor of the kidney. J Natl Cancer Inst, 1972. 48(2): p. 313-24.

18. Solomon, E., Recessive mutation in aetiology of Wilms' tumour. Nature, 1984. 309(5964): p. 111-2.

19. Orkin, S.H., D.S. Goldman, and S.E. Sallan, Development of homozygosity for chromosome 11p markers in Wilms' tumour. Nature, 1984. 309(5964): p. 172-4.

20. Reeve, A.E., et al., Loss of a Harvey ras allele in sporadic Wilms' tumour. Nature, 1984. 309(5964): p. 174-6.

21. Fearon, E.R., B. Vogelstein, and A.P. Feinberg, Somatic deletion and duplication of genes on chromosome 11 in Wilms' tumours. Nature, 1984. 309(5964): p. 176-8. 
22. Eccles, M.R., et al., Harvey-ras allele deletion detected by in situ hybridization to Wilms' tumor chromosomes. Hum Genet, 1984. 67(2): p. 190-2.

23. Chakravarthy, S., et al., Substrate-specific kinetics of Dicer-catalyzed RNA processing. J Mol Biol, 2010. 404(3): p. 392-402.

24. Carthew, R.W., Gene regulation by microRNAs. Curr Opin Genet Dev, 2006. 16(2): p. 203-8.

25. Tang, K.F., et al., Dicer knockdown induces fibronectin-1 expression in HEK293T cells via induction of Egr1. Biochim Biophys Acta, 2010. 1800(3): p. 380-4.

26. Tang, K.F., et al., Upregulation of PHLDA2 in Dicer knockdown HEK293 cells. Biochim Biophys Acta, 2007. 1770(5): p. 820-5.

27. Bahubeshi, A., et al., Germline DICER1 mutations and familial cystic nephroma. J Med Genet, 2010. 47(12): p. 863-6.

28. Wildi-Runge, S., et al., New Phenotype in the Familial DICER1 Tumor Syndrome: Pituitary Blastoma Presenting at Age 9 Months. Endocr Rev, 2011. 32((03_MeetingAbstracts)): p. P1-777.

29. Schultz, K.A., et al., Ovarian sex cord-stromal tumors, pleuropulmonary blastoma and DICER1 mutations: a report from the International Pleuropulmonary Blastoma Registry. Gynecol Oncol, 2011. 122(2): p. 246-50.

30. Carmell, M.A. and G.J. Hannon, RNase III enzymes and the initiation of gene silencing. Nat Struct Mol Biol, 2004. 11(3): p. 214-8.

31. Lau, P.W., et al., The molecular architecture of human Dicer. Nat Struct Mol Biol, 2012. 19(4): p. 436-40.

32. Merritt, W.M., M. Bar-Eli, and A.K. Sood, The dicey role of Dicer: implications for RNAi therapy. Cancer Res, 2010. 70(7): p. 2571-4.

33. Ohishi, K. and T. Nakano, A forward genetic screen to study mammalian RNA interference - essential role of RNase IIIa domain of Dicer1 in 3' strand cleavage of dsRNA in vivo. FEBS J, 2012. 279(5): p. 832-43.

34. Takeshita, D., et al., Homodimeric structure and double-stranded RNA cleavage activity of the C-terminal RNase III domain of human dicer. J Mol Biol, 2007. 374(1): p. 106-20.

35. Macrae, I.J., et al., Structure of Dicer and mechanistic implications for RNAi. Cold Spring Harb Symp Quant Biol, 2006. 71: p. 73-80.

36. Bahubeshi, A., M. Tischkowitz, and W.D. Foulkes, miRNA processing and human cancer: DICER1 cuts the mustard. Sci Transl Med, 2011. 3(111): p. 111ps46.

37. Heravi-Moussavi, A., et al., Recurrent somatic DICER1 mutations in nonepithelial ovarian cancers. N Engl J Med, 2012. 366(3): p. 234-42.

38. Hill, D.A., et al., DICER1 mutations in familial pleuropulmonary blastoma. Science, 2009. 325(5943): p. 965.

39. Don, R.H., et al., 'Touchdown' PCR to circumvent spurious priming during gene amplification. Nucleic Acids Res, 1991. 19(14): p. 4008.

40. Lastella, P., et al., Site directed mutagenesis of hMLH1 exonic splicing enhancers does not correlate with splicing disruption. J Med Genet, 2004. 41(6): p. e72.

41. Gurtan, A.M., et al., In vivo structure-function analysis of human Dicer reveals directional processing of precursor miRNAs. RNA, 2012. 18(6): p. 1116-22.

42. Amrein, L., et al., The phosphatidylinositol-3 kinase I inhibitor BKM120 induces cell death in B-chronic lymphocytic leukemia cells in vitro. Int J Cancer, 2012. 
43. Adzhubei, I.A., et al., A method and server for predicting damaging missense mutations. Nat Methods, 2010. 7(4): p. 248-9.

44. Ng, P.C. and S. Henikoff, Predicting deleterious amino acid substitutions. Genome Res, 2001. 11(5): p. 863-74.

45. Wang, Z., et al., Systematic identification and analysis of exonic splicing silencers. Cell, 2004. 119(6): p. 831-45.

46. Raponi, M., et al., Prediction of single-nucleotide substitutions that result in exon skipping: identification of a splicing silencer in BRCA1 exon 6. Hum Mutat, 2011. 32(4): p. 436-44.

47. Rio Frio, T., et al., DICER1 mutations in familial multinodular goiter with and without ovarian Sertoli-Leydig cell tumors. JAMA, 2011. 305(1): p. 68-77.

48. Sterne-Weiler, T., et al., Loss of exon identity is a common mechanism of human inherited disease. Genome Res, 2011. 21(10): p. 1563-71.

49. Bonnet, C., et al., Screening BRCA1 and BRCA2 unclassified variants for splicing mutations using reverse transcription PCR on patient RNA and an ex vivo assay based on a splicing reporter minigene. J Med Genet, 2008. 45(7): p. 438-46.

50. Harfe, B.D., et al., The RNaseIII enzyme Dicer is required for morphogenesis but not patterning of the vertebrate limb. Proc Natl Acad Sci U S A, 2005. 102(31): p. 10898903.

51. Anglesio, M., et al., Cancer-associated somatic DICER1 hotspot mutations cause defective miRNA processing and reverse strand expression bias to predominantly mature $3 p$ strands through loss of $5 p$ strand cleavage. J Pathol, 2012.

52. Zin, R., et al., SNP-based arrays complement classic cytogenetics in the detection of chromosomal aberrations in Wilms' tumor. Cancer Genet, 2012. 205(3): p. 80-93.

53. de Boer, C.M., et al., DICER1 RNase IIIb domain mutations are infrequent in testicular germ cell tumours. BMC Res Notes, 2012. 5(1): p. 2101791285670510.

54. Vandin, F., E. Upfal, and B.J. Raphael, Finding Driver Pathways in Cancer: Models and Algorithms. Algorithms Mol Biol, 2012. 7(1): p. 23.

55. Kort, E.J., et al., The E2F3-Oncomir-1 axis is activated in Wilms' tumor. Cancer Res, 2008. 68(11): p. 4034-8.

56. Li, J.Y., et al., Review: The role of microRNAs in kidney disease. Nephrology (Carlton), 2010. 15(6): p. 599-608.

57. Senanayake, U., et al., miR-192, miR-194, miR-215, miR-200c and miR-141 are downregulated and their common target ACVR2B is strongly expressed in renal childhood neoplasms. Carcinogenesis, 2012. 33(5): p. 1014-21.

58. Nagalakshmi, V.K., et al., Dicer regulates the development of nephrogenic and ureteric compartments in the mammalian kidney. Kidney Int, 2011. 79(3): p. 317-30.

59. Bartram, M.P., et al., Conditional loss of kidney microRNAs results in congenital anomalies of the kidney and urinary tract (CAKUT). J Mol Med (Berl), 2013. 
Table 1. Prevalence of exonic mutations in DICER1 in sporadic WTs.

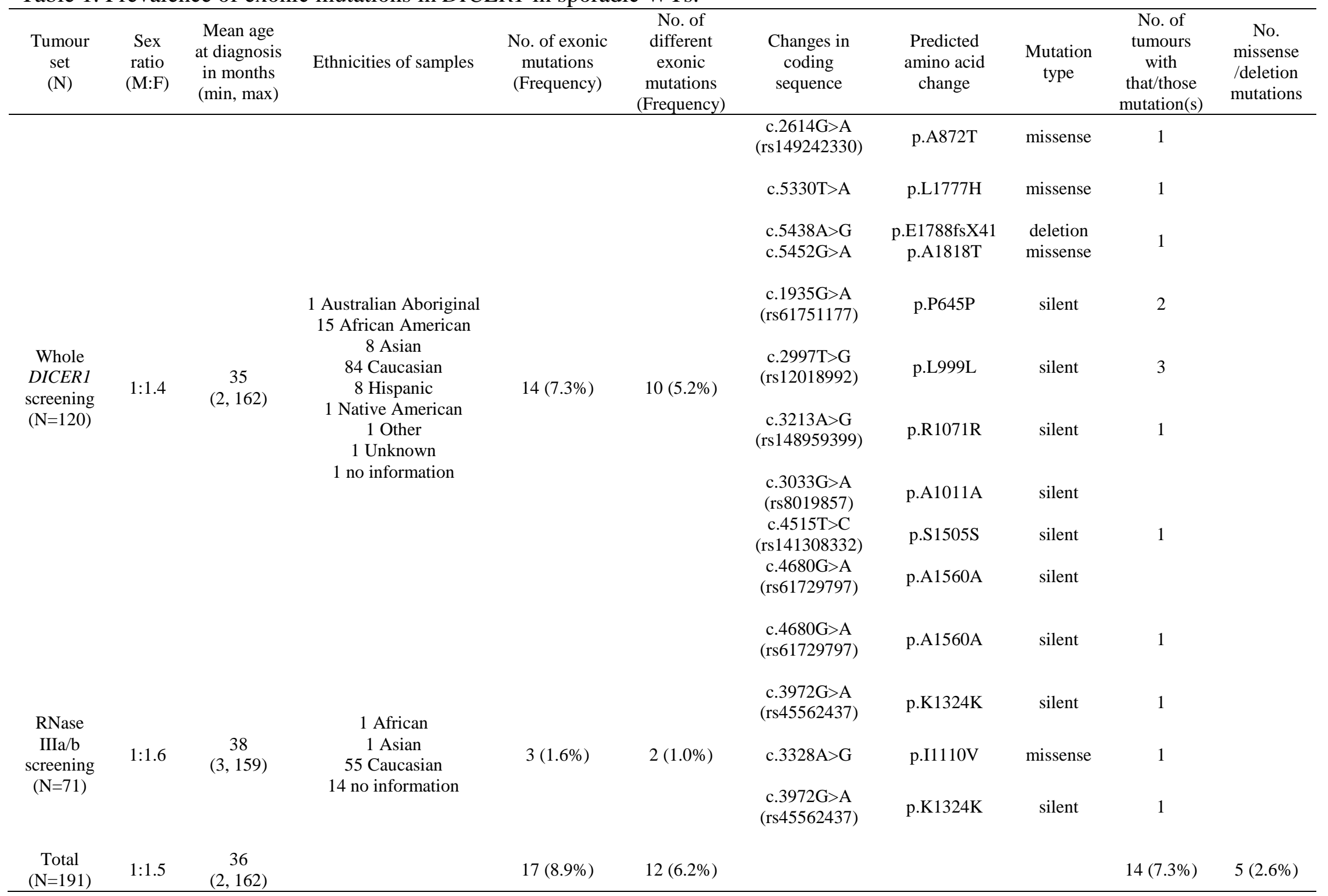


Table 2. Polyphen2 and SIFTBLink predictions for exonic variants seen in sporadic WTs.

\begin{tabular}{|c|c|c|c|c|}
\hline Case & $\begin{array}{l}\text { Somatic mutation and } \\
\text { predicted protein change }\end{array}$ & $\begin{array}{c}\text { Protein domain } \\
\text { affected }\end{array}$ & Polyphen $2^{I}$ & SIFTBLink $^{\text {II }}$ \\
\hline $\mathrm{C}$ & $\begin{array}{c}\text { c. } 2614 \mathrm{G}>\mathrm{A}=\mathrm{rs} 149242330 \\
\text { p.A872T }\end{array}$ & before PAZ & $\begin{array}{c}\text { PROBABLY } \\
\text { DAMAGING } \\
\text { with a score of } 0.999 \\
\text { (sensitivity: } 0.14 ; \\
\text { specificity: } 0.99 \text { ) }\end{array}$ & $\begin{array}{c}\text { TOLERATED } \\
\text { with a score of } 0.33 \text {. } \\
\text { Median sequence } \\
\text { conservation: } 2.04 \\
\text { Sequences represented } \\
\text { at this position:72 }\end{array}$ \\
\hline $\mathrm{M}^{*}$ & c.5330T>A;p.L1777H & RNase IIIb & $\begin{array}{c}\text { POSSIBLY } \\
\text { DAMAGING } \\
\text { with a score of } 0.809 \\
\text { (sensitivity: } 0.84 ; \\
\text { specificity: } 0.93 \text { ) }\end{array}$ & $\begin{array}{l}\text { TOLERATED } \\
\text { with a score of } 0.10 . \\
\text { Median sequence } \\
\text { conservation: } 1.92 \\
\text { Sequences represented } \\
\text { at this position: } 62\end{array}$ \\
\hline $\mathrm{N}$ & c.5438A>G; p.E1788fsX41 & RNase IIIb & $\begin{array}{c}- \\
\text { PROBABLY } \\
\text { DAMAGING } \\
\text { with a score of } 0.997 \\
\text { (sensitivity: } 0.40 ; \\
\text { specificity: } 0.98 \text { ) }\end{array}$ & $\begin{array}{c}- \\
\text { AFFECT PROTEIN } \\
\text { FUNCTION } \\
\text { with a score of } 0.00 . \\
\text { Median sequence } \\
\text { conservation: } 1.93 \\
\text { Sequences represented } \\
\text { at this position:68 }\end{array}$ \\
\hline $\mathrm{X}$ & c.3328A>G; p.I1110V & $\begin{array}{c}\text { Between PAZ } \\
\text { and RNase IIIa }\end{array}$ & $\begin{array}{c}\text { BENIGN } \\
\text { with a score of } 0.000 \\
\text { (sensitivity: } 1.00 ; \\
\text { specificity: } 0.00 \text { ) }\end{array}$ & $\begin{array}{c}\text { TOLERATED } \\
\text { with a score of } 0.30 \text {. } \\
\text { Median sequence } \\
\text { conservation: } 2.28 \\
\text { Sequences represented } \\
\text { at this position:57 }\end{array}$ \\
\hline
\end{tabular}

Ihttp://genetics.bwh.harvard.edu/pph2/index.shtml [43]

II http://sift.jcvi.org/www/SIFT_BLink_submit.html [44] 


\section{Figure legends}

Figure 1 . Hereditary cases of WT (see [8]; case 1 = family 5; case 2 = family 3; case 3 = family 4) . (a) Pedigree for familial case 1 (proband indicated with arrow). (b) Pedigree for familial case

2. (c) Pedigree for familial case 3. (d) Schematic drawing of DICER1 domains showing amino acid positions and position of acquired mutations. (e) Germline and somatic mutations observed in the 3 familial cases of WT. ${ }^{\mathrm{I}}$ Phase of mutations in case 3 was not possible because RNA was not available for this tumour. ${ }^{\mathrm{II}} \mathrm{DNA}$ and other materials for this case provided by A. Charles and C.S. Choong. DUF= domain of unknown function; dsRBD= double stranded RNA binding domain

Figure 2. Missense/deletion mutations in DICER1 in sporadic WTs. ${ }^{\text {iii }}$ sample was FFPE Figure 3. Cloning strategy to demonstrate c.5429A $>\mathrm{G}$ and c.5438A $>\mathrm{G}$ act as exonic splicing silencer sites. (a) diagram of experimental strategy; (b) agarose gel showing RT-PCR products of introduced vectors and sequencing results demonstrating that c.5429A $>\mathrm{G}$ and c.5438A $>\mathrm{G}$ both promote exon 25 exclusion. pSPL3 vector = p; pEX25= pSPL3 containing wildtype exon 25; pTC1 = pSPL3 containing exon 25 with c.5429A > G; p.TC2= pSPL3 containing exon 25 with c.5438A $>$ G.

Figure 4. Western blot of FLAG-tagged DICER constructs. 1= pCAGGS-FLAG; 2= mock; 3= pCAGGS-FLAG-DICER1; 4= pCAGGS-FLAG-deltaexon25 (a) Anti-FLAG blot; (b) anti-Dicer blot. 
Figure 5. Models for DICER1-related WT formation. (a) Model observed in the familial cases 1, 2, and 3, where a germline mutation in DICER1 causes NMD and the acquired mutation affects either the RNase IIIa or RNase IIIb domain; (b) Model observed in somatic case N where specific missense mutations in RNase IIIb is required for WT formation. 
Figure S1. Hereditary WT case 1

Figure S2. Hereditary WT case 2. (a) Pedigree; (b) germline mutation; (c) somatic mutation; (d) cDNA products seen in blood and WT from familial case 2 as well as sequences from gel purified cDNA products; (e) somatic mutation as seen in exon 25 depleted clones; (f) Cloning results.

Figure S3. Hereditary WT case 3. (a) Pedigree; (b) germline mutation; (c) somatic mutations.

Figure S4. Cloning results for somatic WT case N.

Figure S5. Additional ESS sites introduced by single base substitutions c.5429A $>$ G and c.5438A>G. Output files from http://genes.mit.edu/fas-ess/[45]

Figure S6. Silent mutations seen in somatic Wilms tumours. ${ }^{\mathrm{III}}$ DNA extracted from FFPE samples. 


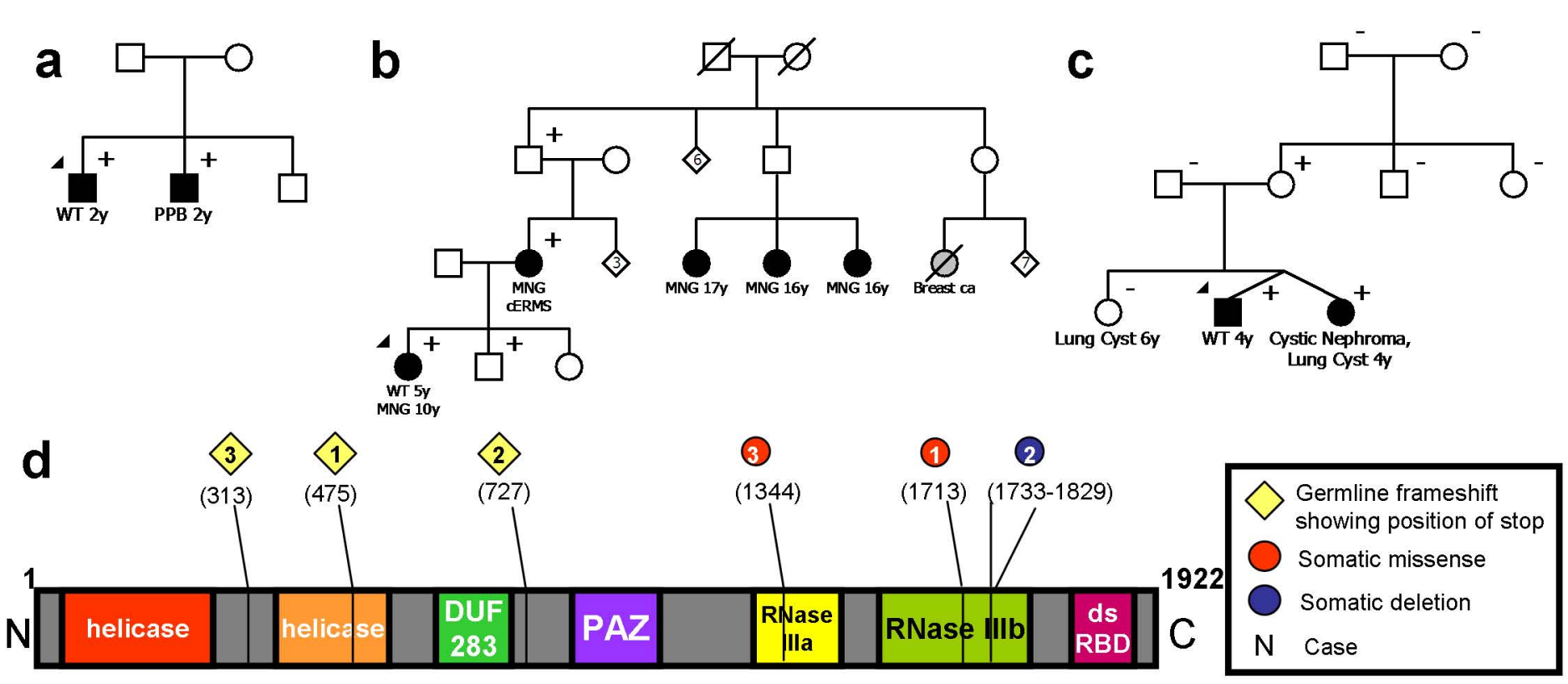

e

\begin{tabular}{|c|c|c|c|c|}
\hline Case & $\begin{array}{l}\text { Germline mutation and } \\
\text { predicted protein change }\end{array}$ & $\begin{array}{l}\text { Somatic mutation and } \\
\text { predicted protein change }\end{array}$ & $\begin{array}{l}\text { Mutations } \\
\text { in cis or } \\
\text { in trans }\end{array}$ & $\begin{array}{l}\text { Domain } \\
\text { affected by } \\
\text { missense }\end{array}$ \\
\hline 1 & $\begin{array}{l}\text { c. } 1306 \text { dupT; } \\
\text { p.S436FfsX41 }\end{array}$ & $\begin{array}{l}\text { c. } 5138 \mathrm{~A}>\mathrm{C} \\
\text { p.D1713A }\end{array}$ & trans & RNAselllb \\
\hline $2^{\prime \prime}$ & $\begin{array}{l}\text { c. } 2117-1 G>A ; \\
\text { p. } G 706 A f s X 8\end{array}$ & $\begin{array}{c}\text { c.5429A>G; } \\
\text { r.5365_5527delCTTAGGAGATCTGAGGAGGATGAAGAGA } \\
\text { AAGAAGAGGATATTGAAGTTCCAAAGGCCATGGGGGAT } \\
\text { ATTTTTGAGTCGCTTGCTGGTGCCATTTACATGGATAGT } \\
\text { GGGATGTCACTGGAGACAGTCTGGCAGGTGTACTATCC } \\
\text { CATGATGCGGCCACTAATAG; } \\
\text { p.E1788fs X41 }\end{array}$ & trans & RNAselllb \\
\hline 3 & $\begin{array}{c}\text { c.912_919dupAGACTGTC; } \\
\text { p.R307Qfs X8 }\end{array}$ & $\begin{array}{l}\text { c. } 4031 \mathrm{C}>\mathrm{T} \\
\text { p. } \$ 1344 \mathrm{~L}\end{array}$ & unknowni & RNAsellla \\
\hline
\end{tabular}

\section{f}

\begin{tabular}{|c|c|c|c|}
\hline Case & Somatic predicted protein change & Polyphen* & SiftBLink ${ }^{* *}$ \\
\hline 1 & p.D1713A & $\begin{array}{c}\text { PROBABLY DAMAGING } \\
\text { with a score of } 0.999 \\
\text { (sensitivity: } 0.14 \text {; specificity: } 0.99 \text { ) }\end{array}$ & $\begin{array}{c}\text { AFFECT PROTEIN FUNCTION } \\
\text { with a score of } 0.00 \text {. } \\
\text { Median sequence conservation: } 1.94 \\
\text { Sequences represented at this position: } 72\end{array}$ \\
\hline 2 & p.E1788fs $\times 41$ & - & - \\
\hline 3 & p.S1344L & $\begin{array}{c}\text { PROBABLY DAMAGING } \\
\text { with a score of } 0.980 \\
\text { (sensitivity: } 0.74 ; \text { specificity: } 0.96 \text { ) }\end{array}$ & $\begin{array}{c}\text { AFFECT PROTEIN FUNCTION } \\
\text { with a score of } 0.00 \text {. } \\
\text { Median sequence conservation: } 1.90 \\
\text { Sequences represented at this position:73 }\end{array}$ \\
\hline
\end{tabular}

Figure 1. Hereditary cases of WT 


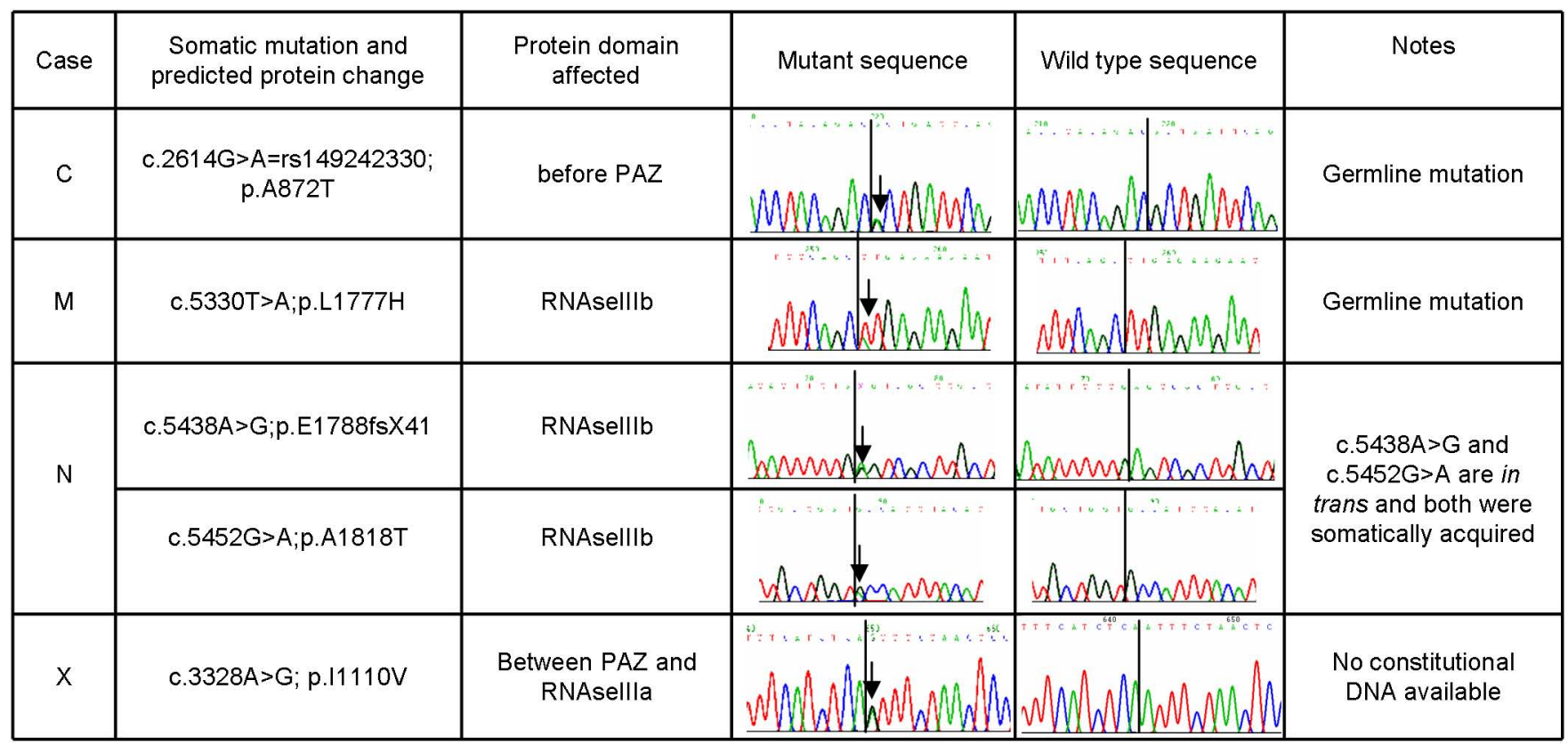

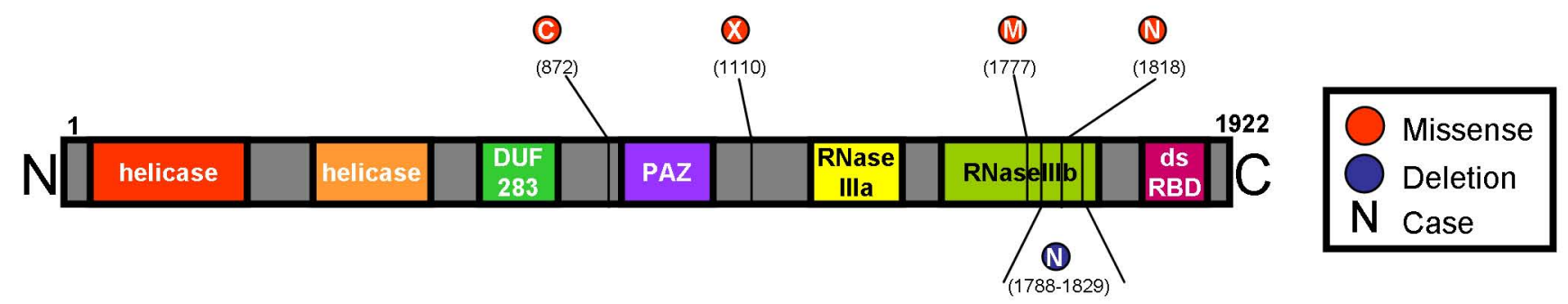

Figure 2. Missense/deletion mutations in DICER1 in sporadic WTs. 
a
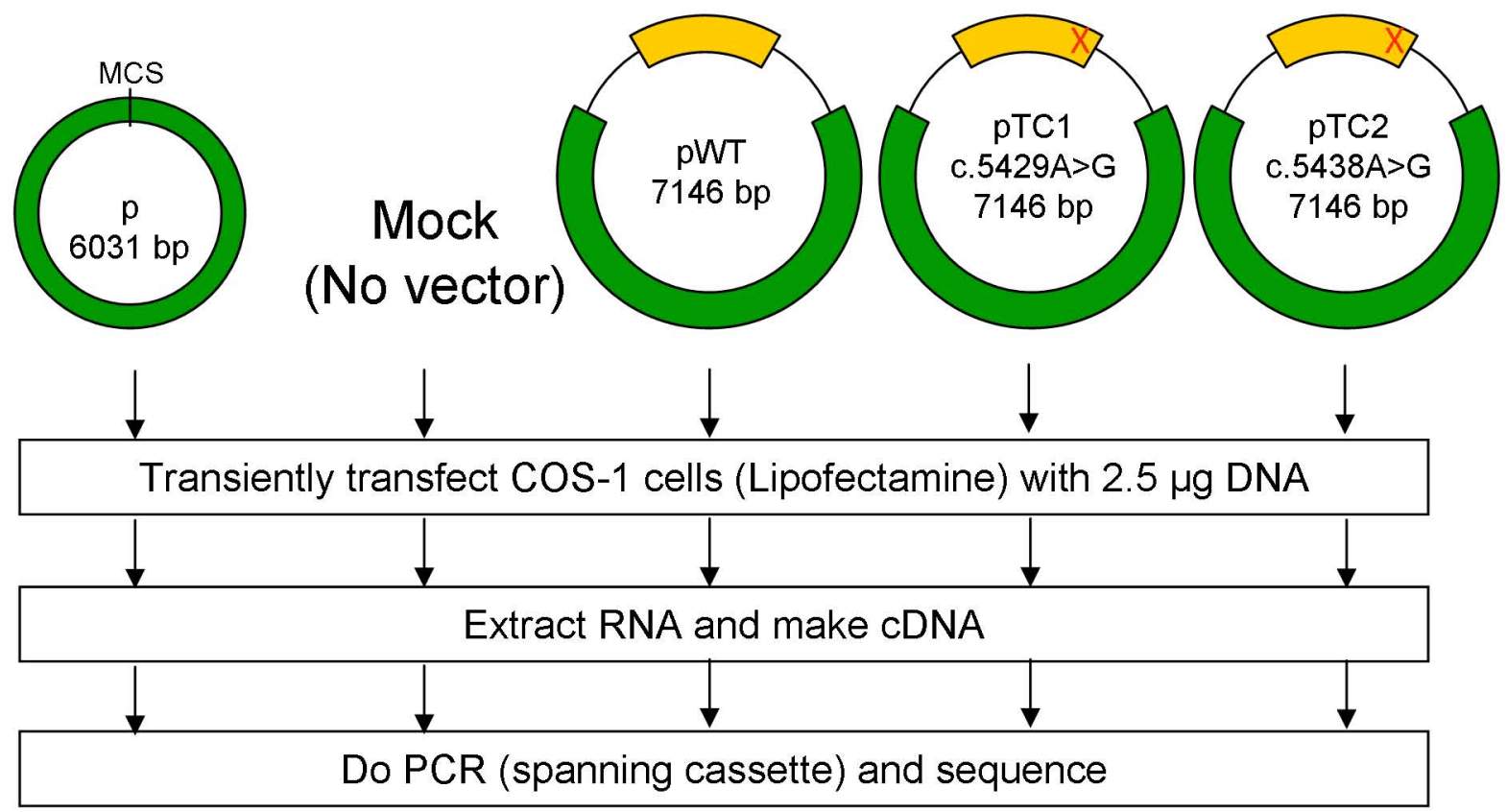

b

p mock pEX25 pTC1 pTC2 $\mathrm{dH}_{2} \mathrm{O}$

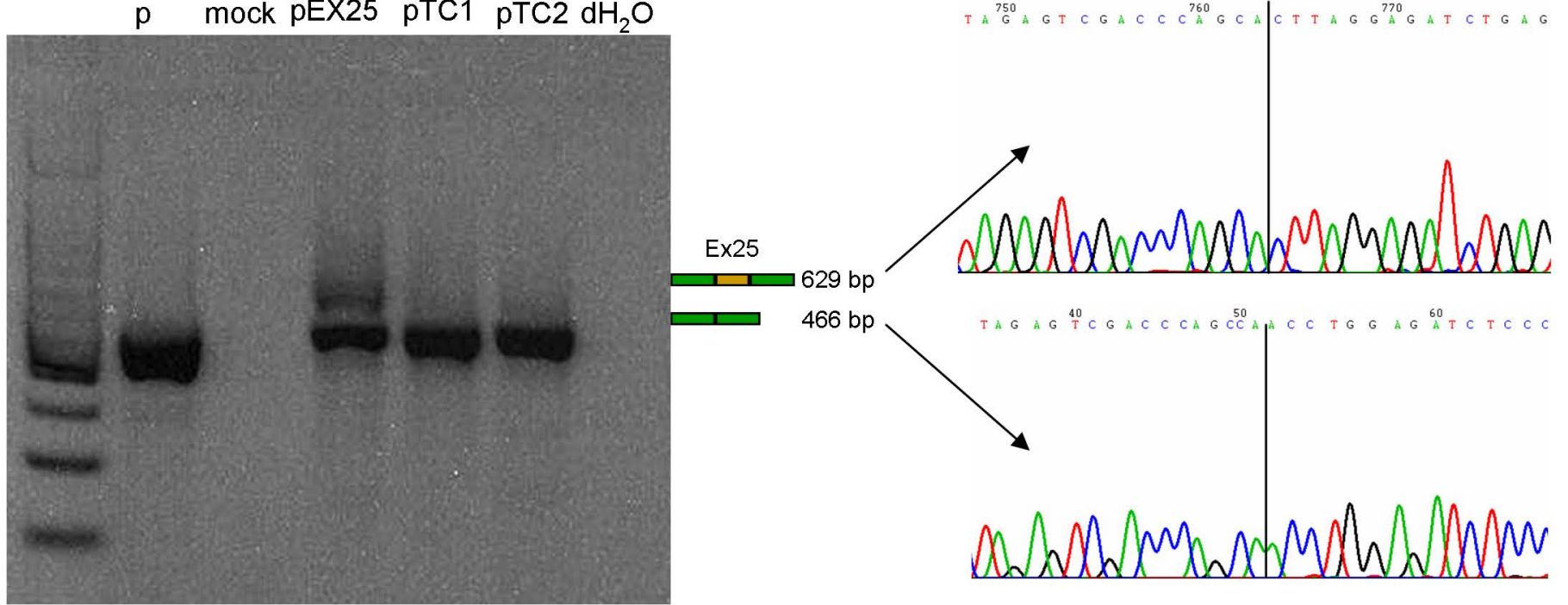

Figure 3. Cloning strategy to demonstrate c.5429A $>\mathrm{G}$ and c.5438A $>\mathrm{G}$ act as exonic splicing silencer sites. 
a
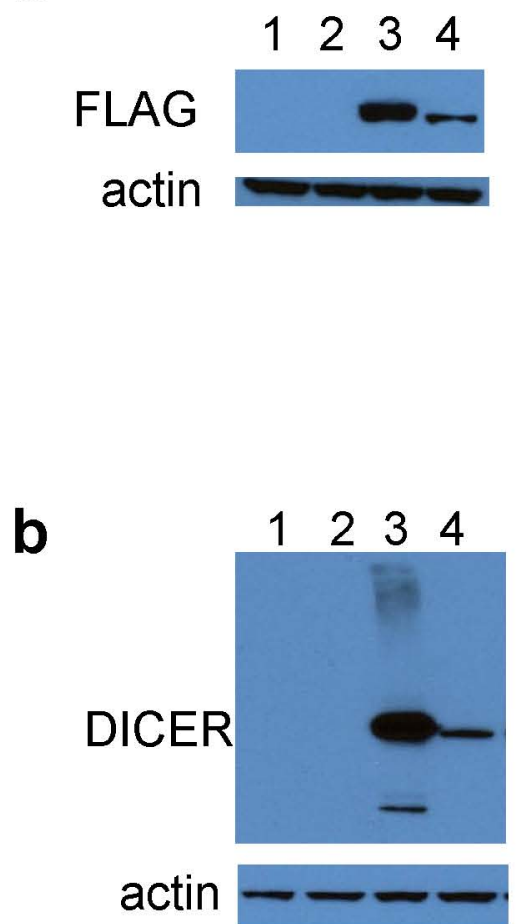

Figure 4. Western blot of FLAG-tagged DICER constructs. 

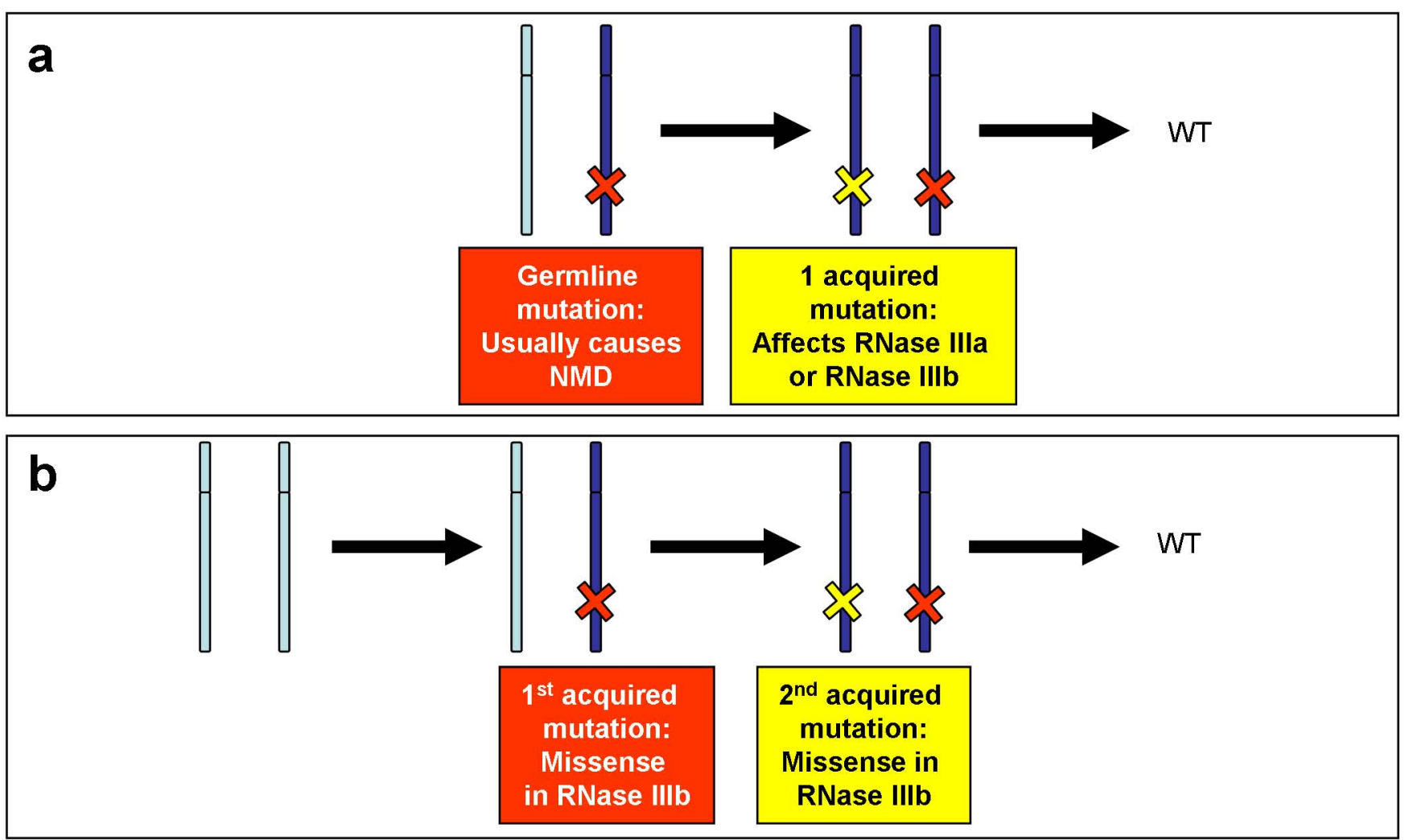

Figure 5. Models for DICER1-related WT formation. 
a

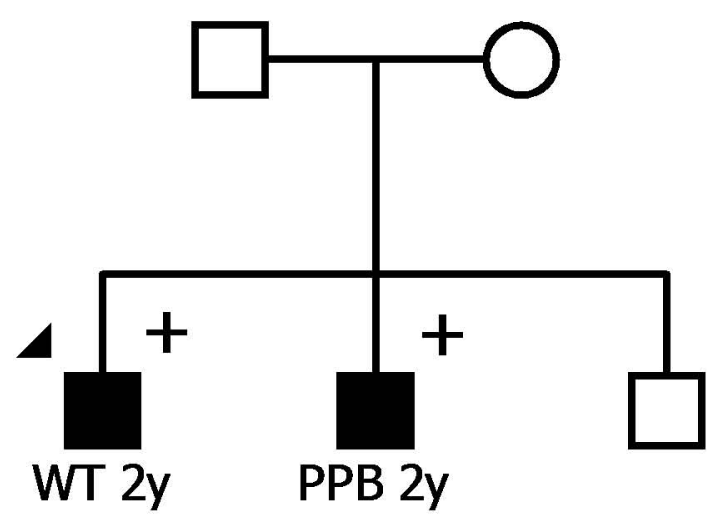

b

Germline mutation

c.1306insT

DNA

$$
\text { c a }
$$

WWWWhwh Whom

Wild type

DNA Mmonswomsmoms

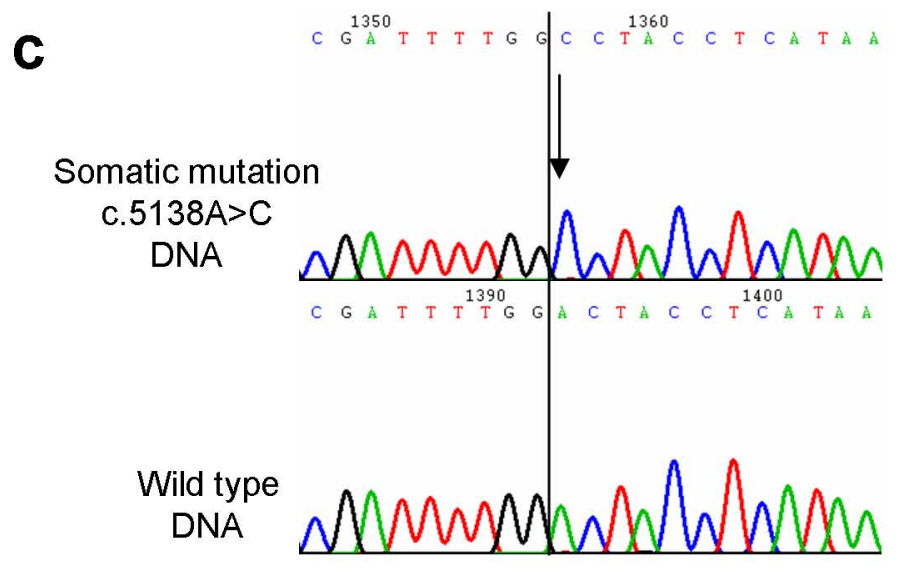

d
Cloning results
\begin{tabular}{|c|c|c|c|}
\hline $\begin{array}{c}\text { C. } 1306 \text { ins T } \\
\text { only }\end{array}$ & $\begin{array}{c}\text { c. } 5138 \mathrm{~A}>\mathrm{C} \\
\text { only }\end{array}$ & $\begin{array}{c}\text { c. } 1306 \text { ins T } \\
+ \\
\text { c. } 5138 \mathrm{~A}>\mathrm{C}\end{array}$ & No mutation \\
\hline 8 & 21 & 0 & 0 \\
\hline
\end{tabular}

Figure S1. Hereditary case 1. 


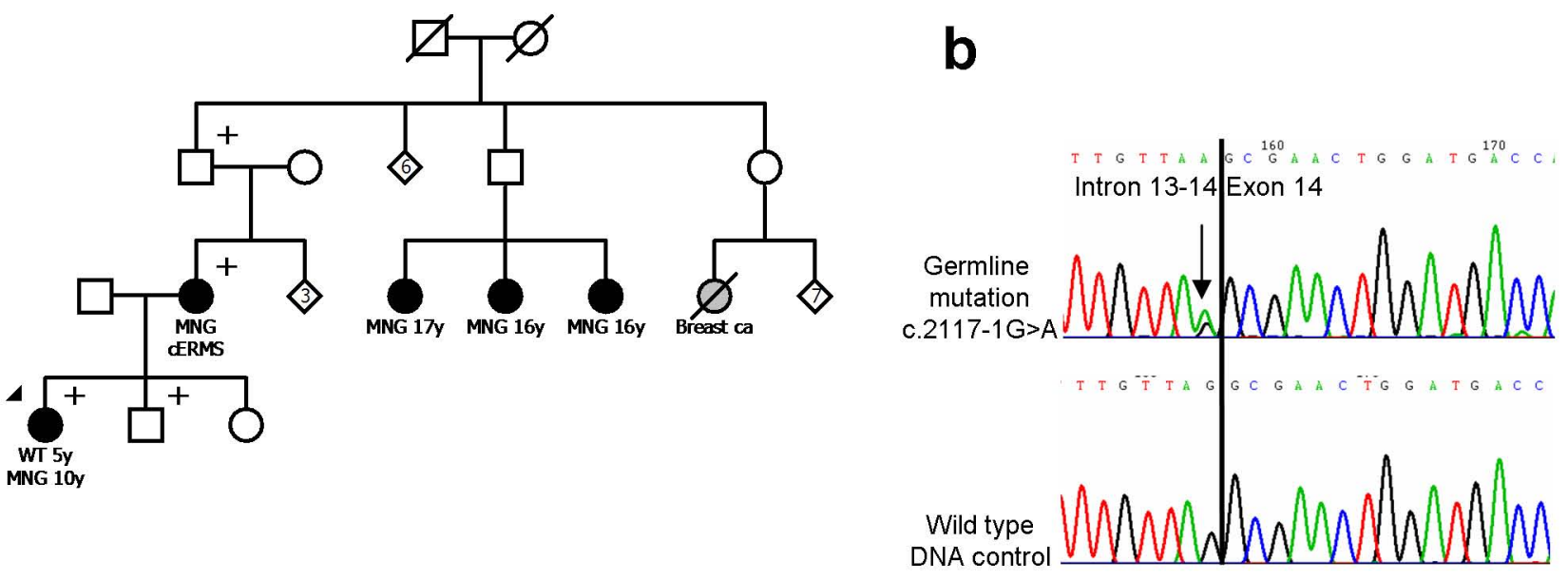

C

Somatic mutation

c. $5429 A>G$ DNA

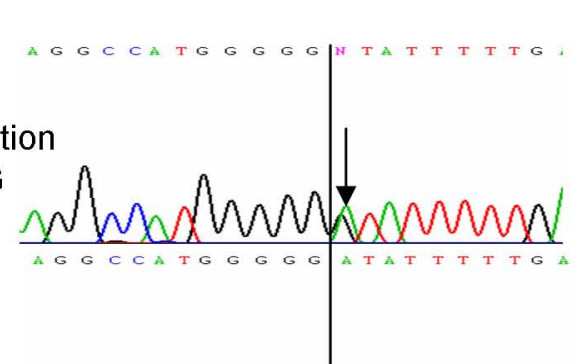

Wild type DNA

whadurbormon
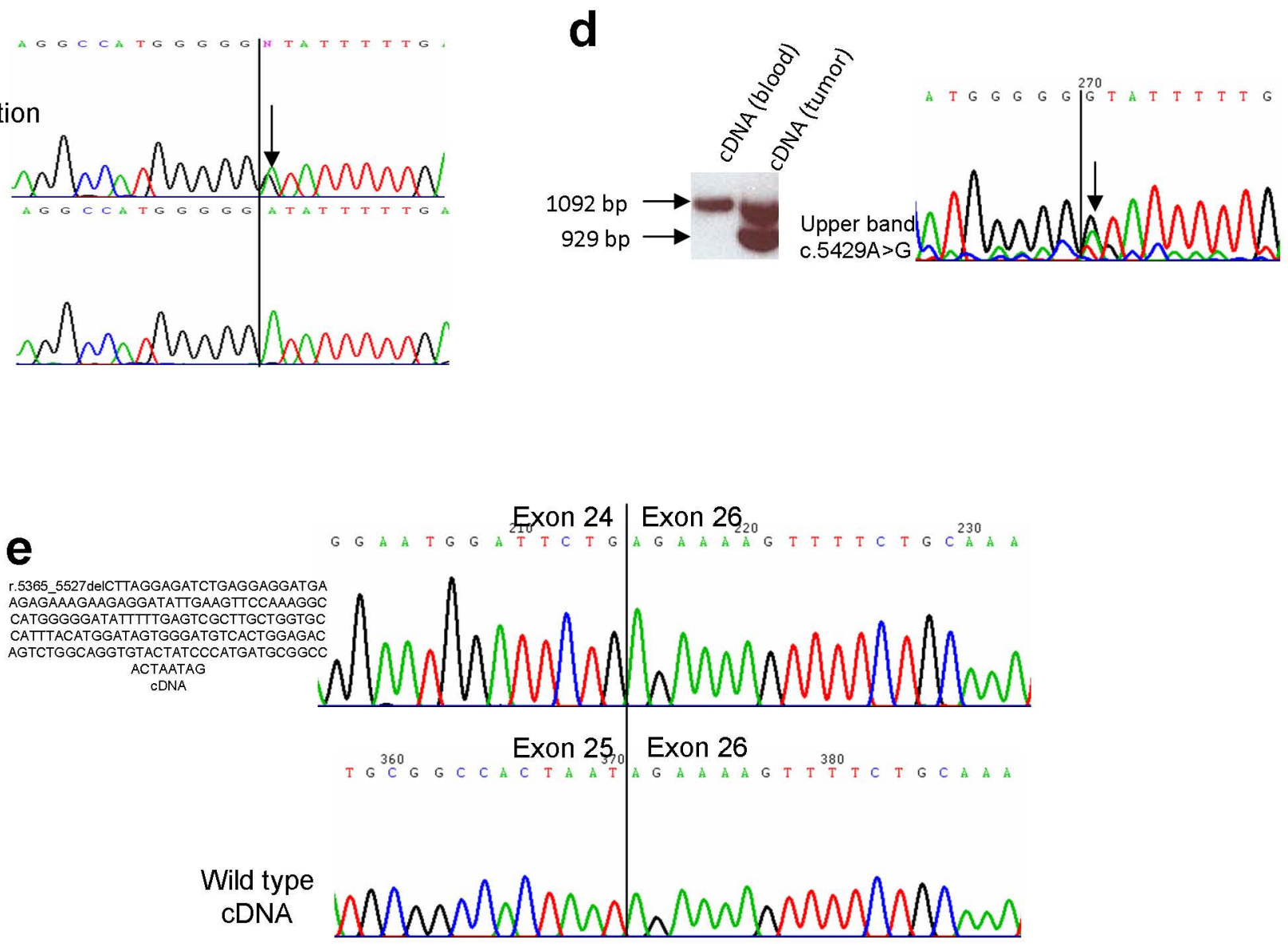

f Cloning results

\begin{tabular}{|c|c|c|c|}
\hline $\begin{array}{c}\text { c. } 2117-1 \mathrm{G}>\mathrm{A} \\
\text { only }\end{array}$ & $\begin{array}{c}\text { Skip exon } 25 \\
\text { only }\end{array}$ & $\begin{array}{c}\text { c.2117-1G>A } \\
+\mathrm{c} .5429 \mathrm{~A}>\mathrm{G}\end{array}$ & No mutation \\
\hline 0 & 5 & 0 & 0 \\
\hline
\end{tabular}

Figure S2. Hereditary case 2. 
a

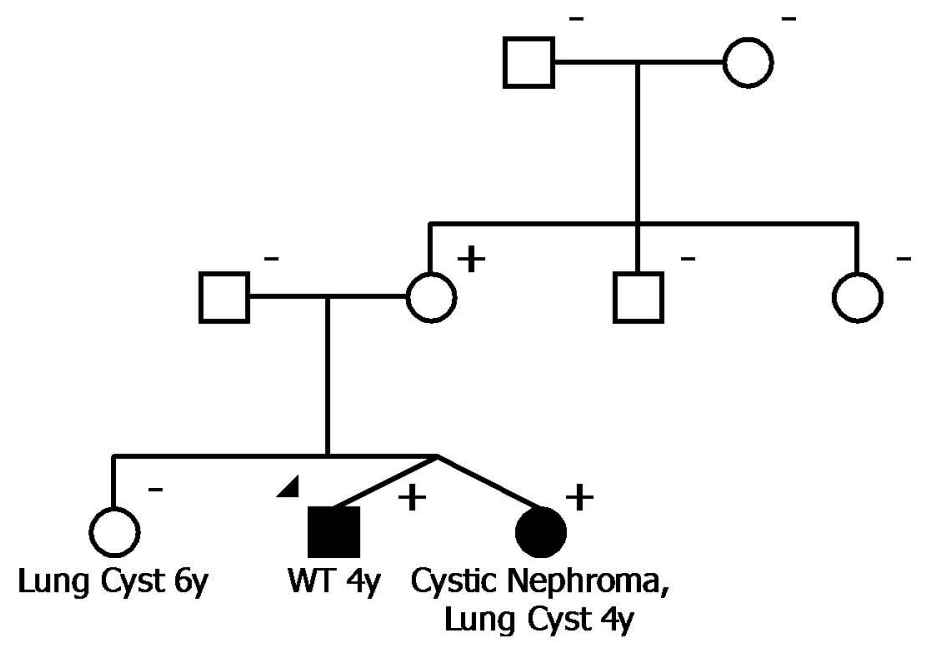

b

Germline mutation c.912_919dupAGACTGTC

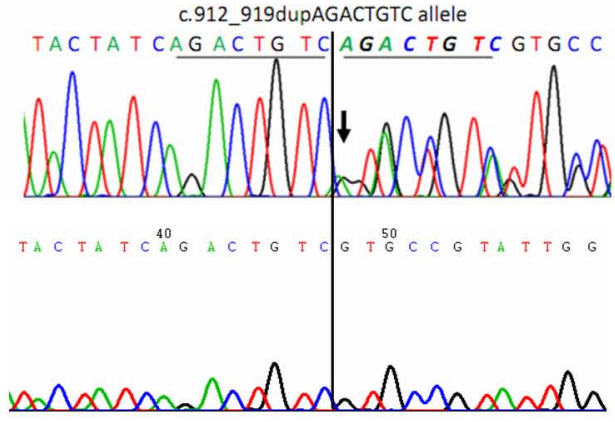

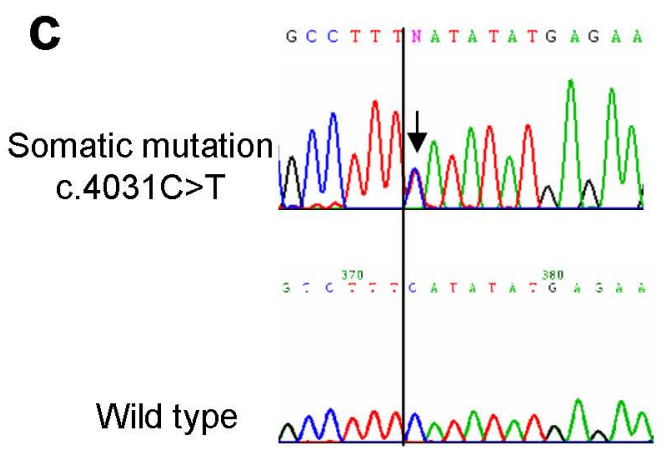

Figure S3. Hereditary case 3. 
Cloning results

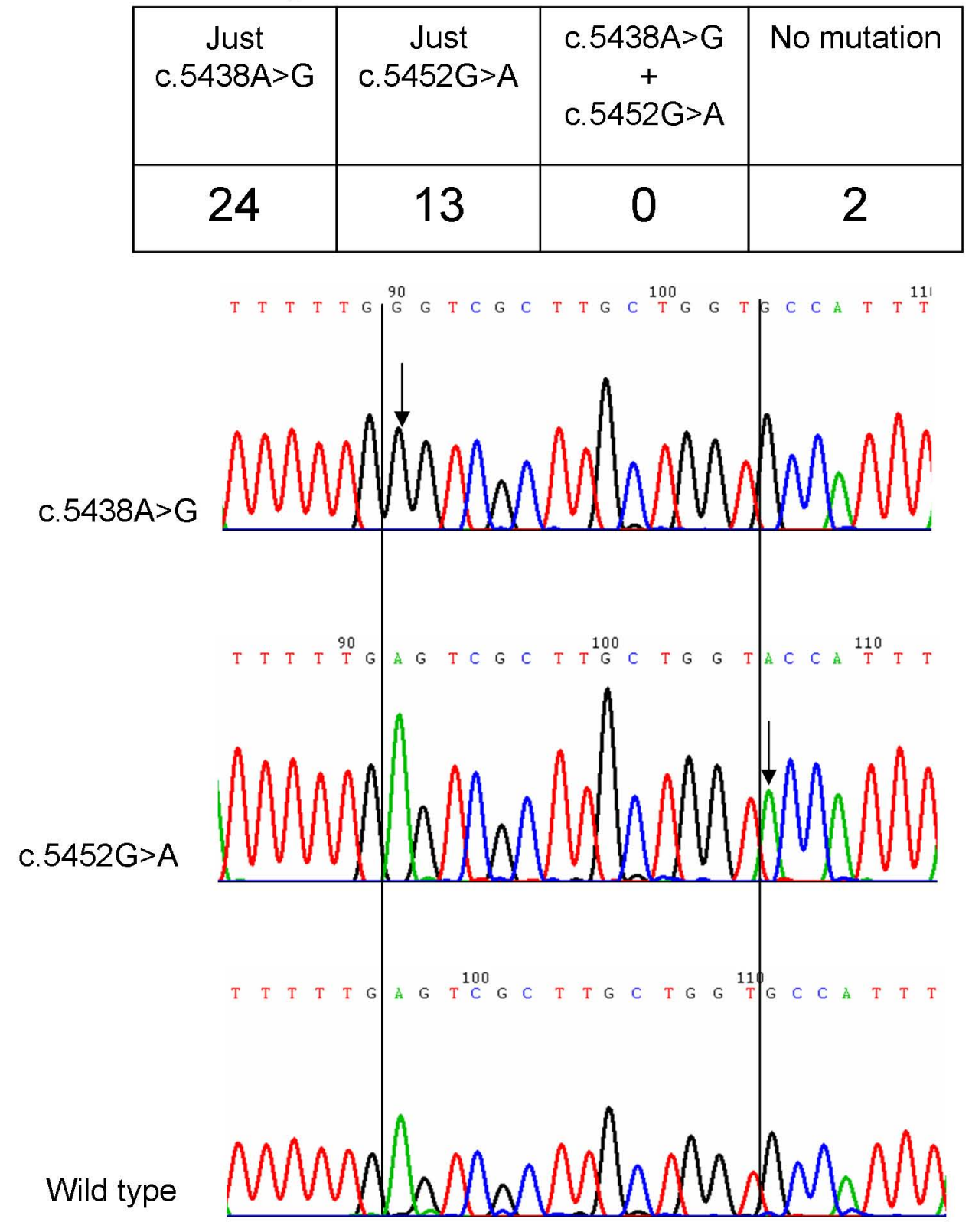

Figure S4. Cloning results for somatic case N. 

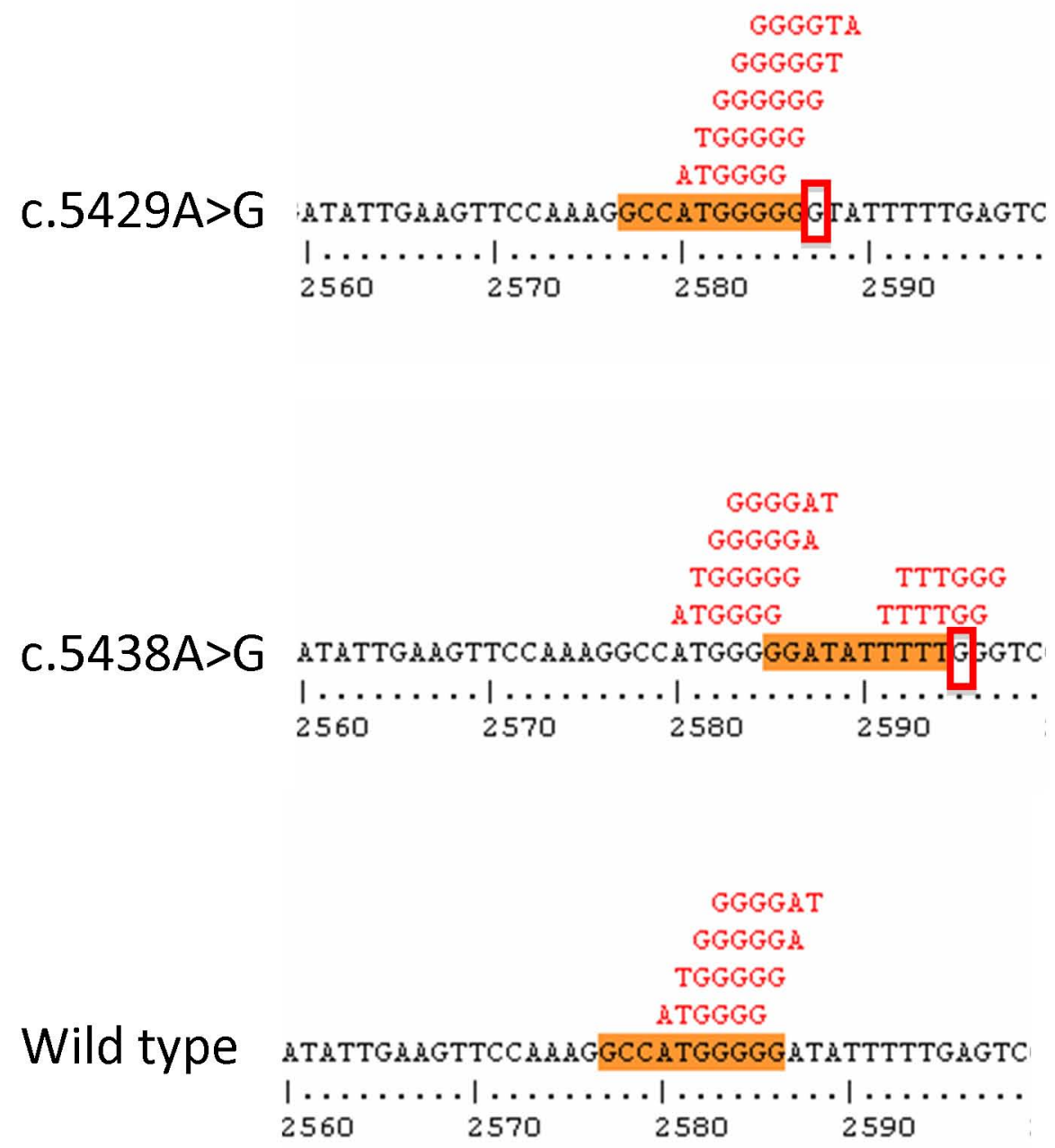

Figure S5. Additional ESS sites introduced by missense mutations c.5429A $>\mathrm{G}$ and c.5438A>G. 


\begin{tabular}{|c|c|c|c|c|c|}
\hline Case & $\begin{array}{l}\text { Somatic mutation and } \\
\text { predicted protein change }\end{array}$ & $\begin{array}{l}\text { Protein domain } \\
\text { affected }\end{array}$ & Mutant sequence & $\begin{array}{l}\text { Wild type } \\
\text { sequence }\end{array}$ & Notes \\
\hline$A, B$ & $\begin{array}{c}\text { c. } 1935 G>A=r s 61751177 \\
\text { p.P645P }\end{array}$ & DUF 283 & & MNA & $\begin{array}{c}\text { Tumour } \\
\text { possesses a } \\
\text { somatic WT1 } \\
\text { mutation }\end{array}$ \\
\hline$D, E$ & $\begin{array}{c}\text { c. } 2997 \mathrm{~T}>\mathrm{G}=\mathrm{rs} 12018992 \\
\text { p.L999L }\end{array}$ & PAZ & & & \\
\hline$F$ & $\begin{array}{c}\text { c. } 2997 \mathrm{~T}>\mathrm{G}=\mathrm{rs} 12018992 \\
\text { p.L999L }\end{array}$ & PAZ & & & $\begin{array}{c}\text { c. } 2997 \mathrm{~T}>\mathrm{G} \\
\text { appears to be } \\
\text { homozygous }\end{array}$ \\
\hline$G$ & $\begin{array}{c}\text { c. } 3213 A>G=r s 148959399 \\
\text { p.R1071R }\end{array}$ & $\begin{array}{l}\text { Between PAZ and } \\
\text { RNase IIla }\end{array}$ & & & germline \\
\hline \multirow{3}{*}{$\mathrm{H}$} & $\begin{array}{c}\text { c. } 3033 \mathrm{G}>\mathrm{A}=\mathrm{rs} 8019857 \\
\text { p. } A 1011 \mathrm{~A}\end{array}$ & $\begin{array}{l}\text { Between PAZ and } \\
\text { RNase IIla }\end{array}$ & & Ald & \\
\hline & $\begin{array}{c}\text { c. } 4515 T>C=r s 141308332 \\
\text { p. } S 1505 S\end{array}$ & $\begin{array}{l}\text { Between RNase } \\
\text { IIla and RNase IIIb }\end{array}$ & & Mhn & $\begin{array}{l}\text { c. } 4514 T>C \\
\text { appears to be } \\
\text { homozygous }\end{array}$ \\
\hline & $\begin{array}{c}\text { c. } 4680 G>A=r s 61729797 \\
\text { p.A1560A }\end{array}$ & $\begin{array}{l}\text { Between RNase } \\
\text { IIla and RNase IIIb }\end{array}$ & nommes & Nonmbunmm & \\
\hline Iiii $^{\text {iii }}$ & $\begin{array}{c}\text { c. } 3972 \mathrm{G}>\mathrm{A}=\mathrm{rs} 45562437 \\
\text { p. } \mathrm{K} 1324 \mathrm{~K}\end{array}$ & RNase IIla & mangen & 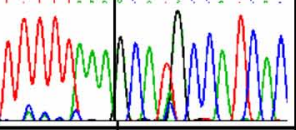 & \\
\hline Wiii $^{\mathrm{iii}}$ & $\begin{array}{c}\text { c. } 3972 \mathrm{G}>\mathrm{A}=\mathrm{rs} 45562437 \\
\text { p. } \mathrm{K} 1324 \mathrm{~K}\end{array}$ & RNase IIla & 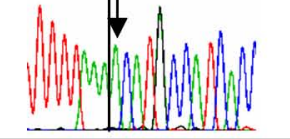 & 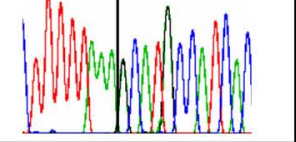 & germline \\
\hline J & $\begin{array}{c}\text { c. } 4680 G>A=r s 61729797 \\
\text { p.A1560A }\end{array}$ & $\begin{array}{l}\text { Between RNase } \\
\text { IIla and RNase IIIb }\end{array}$ & monowndadsd & womnlummons & \\
\hline
\end{tabular}

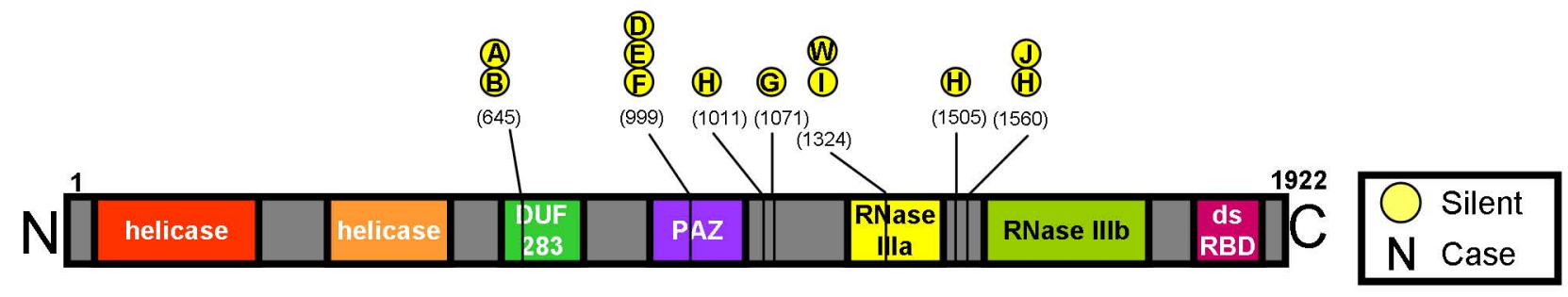

Figure S6. Silent mutations seen in somatic Wilms tumours. "IDNA extracted from FFPE samples. 
Table S1. Additional PCR primers used to screen DICER1.

\begin{tabular}{cll}
\hline Exon & Forward primer & Reverse primer \\
\hline 3 & 5'-TTTTTGTAAATTTATGGAGGACGA-3' & 5'- TGCCAGAAGAGATTAAATGAGTACA-3' \\
7 & 5'-CCCCACTGCTAACATTCTGGC-3' & 5'- GAGCCGCATTAAGCATATTTC-3' \\
10 & 5'- GGATTTAGAATGCCCAAGAGC-3' & 5'- CCTCTTTTGAGATTATTGCCTGT-3' \\
22 & 5'- TTACTGAATTCAGTGAAAAGACAGTG-3' & 5'- TGAATGGGTAGAAAAACTGTAGAGC-3' \\
\hline
\end{tabular}


Table S2. Primers used to screen DICER1 RNase IIIa and RNase IIIb for FFPE samples.

\begin{tabular}{lll}
\hline Domain & Forward primer & Reverse primer \\
\hline \multirow{5}{*}{ RNase IIIb } & 5'-GGGGATCAGTTGCTATGTGG-3' & 5'-CGGGTCTTCATAAAGGTGCT-3' \\
& 5'-ACTTCGGATCCCCTCAGATT-3' & 5'-CGATGCAAAGATGGTGTTGT-3' \\
& 5'-CGCTTAGAATTCCTGGGAGA-3' & 5'-TGACATGGAAGAGCTCAGGA-3' \\
& 5'-CGCTGGCTGTAAAGTACGAC-3' & 5'-TGCCGTCAGAACTCTGAAAC-3' \\
& 5'-GGCCTTTTTGCTTACAAGTCAC-3' & 5'-ATTAGTGGCCGCATCATGG-3' \\
& 5'-TCACCTTATATCGGGGTTTGA-3' & 5'-CACGATGAGATCAACACAAAGTC-3' \\
& & \\
RNase IIIa & & \\
& 5'-GCAGAGCCCTTCTATTGGGTA-3' & 5'-GCATCAGGGTAAGTGCAAAAT-3' \\
& 5'-CTTGAAATGCTTGGCGACTC-3' & 5'-CAAACCACTTTCAGGCACACT-3' \\
& 5'-GGTAGAAAAACTGTAGAGCCCTTA-3' & 5'-GAGGAAGCCAATTCACAGG-3' \\
\hline
\end{tabular}


Table S3. Intronic variants seen in sporadic WTs

\begin{tabular}{|c|c|}
\hline Variation & \% carrying variation \\
\hline rs114886684 & 0.51 \\
\hline c. $438+18 A>G$ & 0.51 \\
\hline c. $439-134 \mathrm{~T}>\mathrm{C}$ & 0.51 \\
\hline c. $573+96 \mathrm{C}>\mathrm{A}$ & 2.55 \\
\hline c. $573+114 \mathrm{~T}>\mathrm{A}$ & 6.63 \\
\hline с. $573+113$ 115delTGinsAA & 4.08 \\
\hline rs11734987̄ & 0.51 \\
\hline c.1377-93_94insA & 0.51 \\
\hline rs192490028I & 1.02 \\
\hline rs2275182 & 17.35 \\
\hline rs11624081 & 7.14 \\
\hline rs74899136 & 1.53 \\
\hline rs188856063 & 0.51 \\
\hline rs57681406 & 1.02 \\
\hline rs112284114 & 0.51 \\
\hline c.2040+58_59delT & 0.51 \\
\hline c. $2040+60 C>T$ & 0.51 \\
\hline c.2040+60_61insT & 3.57 \\
\hline c. $2040+107 \mathrm{C}>\mathrm{A}$ & 0.51 \\
\hline rs2297730 & 21.94 \\
\hline c.2116+61_62insA & 3.57 \\
\hline rs17091823 & 1.02 \\
\hline c. $2256+95 \mathrm{C}>\mathrm{T}$ & 0.51 \\
\hline rs117996122 & 2.04 \\
\hline c. $2804+66 C>A$ & 0.51 \\
\hline rs113189950 & 0.51 \\
\hline c.2805-217_219delAAT & 1.02 \\
\hline c. $2805-70 \mathrm{C}>\mathrm{T}$ & 0.51 \\
\hline c.2805-87_89delCAT & 0.51 \\
\hline rs142857015 & 0.51 \\
\hline c. $2988-93 \mathrm{~T}>\mathrm{C}$ & 0.51 \\
\hline c.3093+149_153delGTTTT & 0.51 \\
\hline c. $3093+221 \mathrm{~A}>\mathrm{G}$ & 0.51 \\
\hline c.3094-8_11delTTAC & 0.51 \\
\hline c. $4051-39 A>T$ & 0.51 \\
\hline c. $4051-24 G>T$ & 0.51 \\
\hline c.4206+5_6insTT & 3.06 \\
\hline rs1778057 & 3.06 \\
\hline c. $4206+21 G>T$ & 0.51 \\
\hline c.5096-49_50delG & 0.51 \\
\hline c. $5096-41 \bar{G}>\mathrm{T}$ & 0.51 \\
\hline c.5364+51_52delCT & 0.51 \\
\hline c. $5527+7 \mathrm{~T}>\mathrm{A}$ & 0.51 \\
\hline rs13078 & 59.69 \\
\hline c.5769+67G>A & 0.51 \\
\hline
\end{tabular}

this variant has previously been reported to be a splice mutation but detailed studies performed showed that it has no effect on splicing (data not shown) 
Table S4. Characteristics of reported WTs with germline DICER1 mutations

\begin{tabular}{|c|c|c|c|c|c|c|c|}
\hline Case & $\begin{array}{c}\text { Age at } \\
\text { diagnosis }\end{array}$ & Histology & $\begin{array}{c}\text { Germline mutation and predicted } \\
\text { protein change }\end{array}$ & $\begin{array}{c}\text { Somatic mutation, predicted protein change } \\
\text { and domain involved }\end{array}$ & $\begin{array}{l}\text { Other diagnoses in } \\
\text { WT patient }\end{array}$ & $\begin{array}{c}\text { Other diagnoses in } \\
\text { family }\end{array}$ & Reference \\
\hline 1 & $2 \mathrm{Y}$ & $\begin{array}{l}\text { Triphasic nephroblastoma with a prominent } \\
\text { blastemal component; scattered areas dominated by } \\
\text { immature tubules with primitive to more mature } \\
\text { epithelium. No evidence of anaplasia. No evidence } \\
\text { of nephrogenic rests. No involvement of one regional } \\
\text { lymph node. Adjacent uninvolved kidney normal. }\end{array}$ & $\begin{array}{l}\text { c.1306dupT; } \\
\text { p.S436FfsX41 }\end{array}$ & $\begin{array}{l}\text { c.5138A }>\text { C; } \\
\text { p.D1713A } \\
\text { RNaseIIIb }\end{array}$ & (1)- & PPB in brother & A \\
\hline 2 & $5 Y$ & $\begin{array}{l}\text { Triphasic nephroblastoma. No evidence of anaplasia. } \\
2 \text { of } 7 \text { regional lymph nodes involved. No } \\
\text { rhabdomyoblastic differentiation. No evidence of } \\
\text { nephrogenic rests. }\end{array}$ & $\begin{array}{l}\text { c.2117-1G>A; } \\
\text { p.G706AfsX8 }\end{array}$ & $\begin{array}{c}\text { c.5429A>G; } \\
\text { r.5365_5527delCTTAGGAGATCTGAGG } \\
\text { AGGATGAAGAGAAAGAAGAGGATAT } \\
\text { TGAAGTTCCAAAGGCCATGGGGGAT } \\
\text { ATTTTTGAGTCGCTTGCTGGTGCCAT } \\
\text { TTACATGGATAGTGGGATGTCACTGG } \\
\text { AGACAGTCTGGCAGGTGTACTATCCC } \\
\text { ATGATGCGGCCACTAATAG; } \\
\text { p.E1788fsX41 } \\
\text { RNaseIIIb }\end{array}$ & MNG & $\begin{array}{l}\text { MNG + } \\
\text { cERMS in } \\
\text { mother; MNG } \\
\text { in } 3 \text { maternal } \\
\text { aunts }\end{array}$ & A \\
\hline 3 & $4 \mathrm{Y}$ & $\begin{array}{l}\text { Triphasic nephroblastoma with a predominant } \\
\text { primitive blastemal component (comprising } 2 / 3 \text { of } \\
\text { the tumor), with primitive tubular structures and } \\
\text { focal spindle cells indicating the presence of } \\
\text { epithelial and stromal components respectively. } \\
\text { Diffuse anaplasia, mostly involving blastema but } \\
\text { focally mesenchymal tumor cells, with markedly } \\
\text { enlarged hyperchromatic nuclei and multipolar } \\
\text { mitotic figures. No evidence of nephroblastomatosis. }\end{array}$ & $\begin{array}{l}\text { c.912_919dupAGACTGTC; } \\
\text { p.R307QfsX8 }\end{array}$ & $\begin{array}{l}\text { c. } 4031 \mathrm{C}>\mathrm{T} \text {; } \\
\text { p.S1344L } \\
\text { RNaseIIIa }\end{array}$ & - & $\begin{array}{l}\mathrm{CN}+\text { lung } \\
\text { cyst in sister }\end{array}$ & A \\
\hline 4 & $2 Y$ & $\begin{array}{l}\text { Markedly necrotic WT tumor with variation in } \\
\text { differentiation of tumor tissue with areas of } \\
\text { differentiation into cartilage with whorls of tumor } \\
\text { suggesting smooth muscle tumor; areas also } \\
\text { suggesting osteoid and rhabdomyosarcoma. No } \\
\text { involvement of several lymph nodes. } \\
\text { (operation carried out in 1973) }\end{array}$ & $\begin{array}{l}\text { c.3079_3080delCT; } \\
\text { p.L1027AfsX3 }\end{array}$ & Tumour not available & MNG at age 17 & $\mathrm{CN}$ in son & B \\
\hline 5 & $8 \mathrm{Y}$ & “Atypical histology” & c.2988-2_2988-1delAGinsCT & Not reported & $\begin{array}{l}\text { MNG + R ovarian } \\
\text { SLCT + L ovarian } \\
\text { SLCT }\end{array}$ & None reported & $\mathrm{C}$ \\
\hline 6 & $3 Y$ & $\begin{array}{l}\text { WT, not otherwise described, with invasion of the } \\
\text { renal vein and three lymph node metastases } \\
\text { (operation carried out in 1964) }\end{array}$ & $\begin{array}{l}\text { c.2379T }>\text { G; } \\
\text { p.Y793X }\end{array}$ & Tumour not available & $\begin{array}{c}\text { R ovarian cyst } \\
\text { (endometriosis) } \\
\text { Removed at age } 23 \text {. } \\
\text { 35mm peripelvic cyst } \\
\text { in remaining } L \\
\text { kidney }\end{array}$ & $\begin{array}{c}\text { numerous } \\
\text { extended family } \\
\text { members affected; } \\
\text { pituitary blastoma; } \\
\text { PPB + CN; MNG; } \\
\text { ovarian tumour } \\
\text { (possibly SLCT) + } \\
\text { "thyroid } \\
\text { problems" + } \\
\text { "calcified } \\
\text { kidney"; SLCT }\end{array}$ & $\mathrm{D}$ \\
\hline
\end{tabular}

A= Foulkes et al., 2011; B = TY Tan, personal communication; C= Slade et al., 2011; D = Wildi-Runge et al., 2011 (WT not described in this report)

SLCT - Sertoli-Leydig cell tumour; MNG - multinodular goitre, cERMS - cervical embryonal rhabdomyosarcoma; CN - cystic nephroma, PPB - pleuropulmonary blastoma 